\title{
Petrophysical interpretation and fluid substitution modelling of the upper shallow marine sandstone reservoirs in the Bredasdorp Basin, offshore South Africa
}

\author{
Moses Magoba ${ }^{1} \cdot$ Mimonitu Opuwari $^{1}$
}

Received: 26 April 2019 / Accepted: 26 October 2019 / Published online: 7 November 2019

(c) The Author(s) 2019

\begin{abstract}
The fluid substitution method is used for predicting elastic properties of reservoir rocks and their dependence on pore fluid and porosity. This method makes it possible to predict changes in elastic response of a rock saturation with different fluids. This study focused on the Upper Shallow Marine sandstone reservoirs of five selected wells (MM1, MM2, MM3, MM4, and MM5) in the Bredasdorp Basin, offshore South Africa. The integration of petrophysics and rock physics (Gassmann fluid substitution) was applied to the upper shallow marine sandstone reservoirs for reservoir characterisation. The objective of the study was to calculate the volume of clay, porosity, water saturation, permeability, and hydrocarbon saturation, and the application of the Gassmann fluid substitution modelling to determine the effect of different pore fluids (brine, oil, and gas) on acoustic properties (compressional velocity, shear velocity, and density) using rock frame properties. The results showed average effective porosity ranging from $8.7 \%$ to $16.6 \%$, indicating a fair to good reservoir quality. The average volume of clay, water saturation, and permeability values ranged from $8.6 \%$ to $22.3 \%, 18.9 \%$ to $41.6 \%$, and $0.096-151.8 \mathrm{mD}$, respectively. The distribution of the petrophysical properties across the field was clearly defined with MM2 and MM3 revealing good porosity and MM1, MM4, and MM5 revealing fair porosity. Well MM4 revealed poor permeability, while MM3 revealed good permeability. The fluid substitution affected rock property significantly. The primary velocity, Vp, slightly decreased when brine was substituted with gas in wells MM1, MM2, MM3, and MM4. The shear velocity, Vs, remained unaffected in all the wells. This study demonstrated how integration of petrophysics and fluid substitution can help to understand the behaviour of rock properties in response to fluid saturation changes in the Bredasdorp Basin. The integration of these two disciplines increases the obtained results' quality and reliability.
\end{abstract}

Keywords Bredasdorp Basin · Bulk density $\cdot$ Compressional velocity $\cdot$ Pore fluid $\cdot$ Porosity $\cdot$ Upper shallow marine

\section{Introduction}

The integration of petrophysics and rock physics studies is significant in the evaluation of well and field development and to generate subsurface models based on rock properties (Khan and Rehman 2018). The fluid substitution method is an important method for predicting elastic properties of reservoir rocks and their dependence on pore fluid and porosity. This method makes it possible to predict changes in elastic response of a rock saturation with different fluids

Mimonitu Opuwari

mopuwari@uwc.ac.za

1 Department of Earth Sciences, University of the Western Cape, Cape Town, South Africa
(Gommesen et al. 2002). The Gassmann fluid substitution method is probably the most well-known rock physics model, and it is used to predict how $\mathrm{P}$ and $\mathrm{S}$ waves change as saturation changes (Purnamasari et al. 2014). Modelling the changes in the elastic properties is possible mainly because of the huge sensitivity of the bulk modulus to saturation changes (Bodunde and Enikanselu 2018). In this study, Gassmann fluid substitution model was applied in well log and rock physics model. The study's overall objective was to calculate the volume of clay $(\mathrm{Vcl})$, porosity, water saturation, permeability, and hydrocarbon saturation, and the application of the Gassmann fluid substitution modelling to determine the effect of different pore fluids (brine, oil, and gas) on acoustic properties (compressional velocity, shear velocity, and density). Additionally, the effect of water saturation on acoustic properties was also investigated. The field of rock 
physics represents the link between qualitative geological parameters and quantitative geophysical measurements. Increasingly over the last decade, rock physics stands out as a key technology in petroleum geophysics, as it has become an integral part of quantitative seismic interpretation (Jensen et al. 2016). Petrophysics is the study of rock principles and their interactions with fluids (oil, gas, or water) (Rider 2002). Petrophysical interpretation transforms a well's log measurements into reservoir properties (e.g. porosity, permeability, saturation, mineral component volume, and $\mathrm{Vcl}$ ) (Bisht et al. 2013). Petrophysics uses different types of logs and core plugs and integrates all pertinent information. It uses wellbore measurements to contribute to reservoir characterisation (Dewar 2001). The reservoir is characterised in terms of reservoir elements such as structural model, well data and fluid properties (Dakhelpour-Ghoveifel et al. 2018).

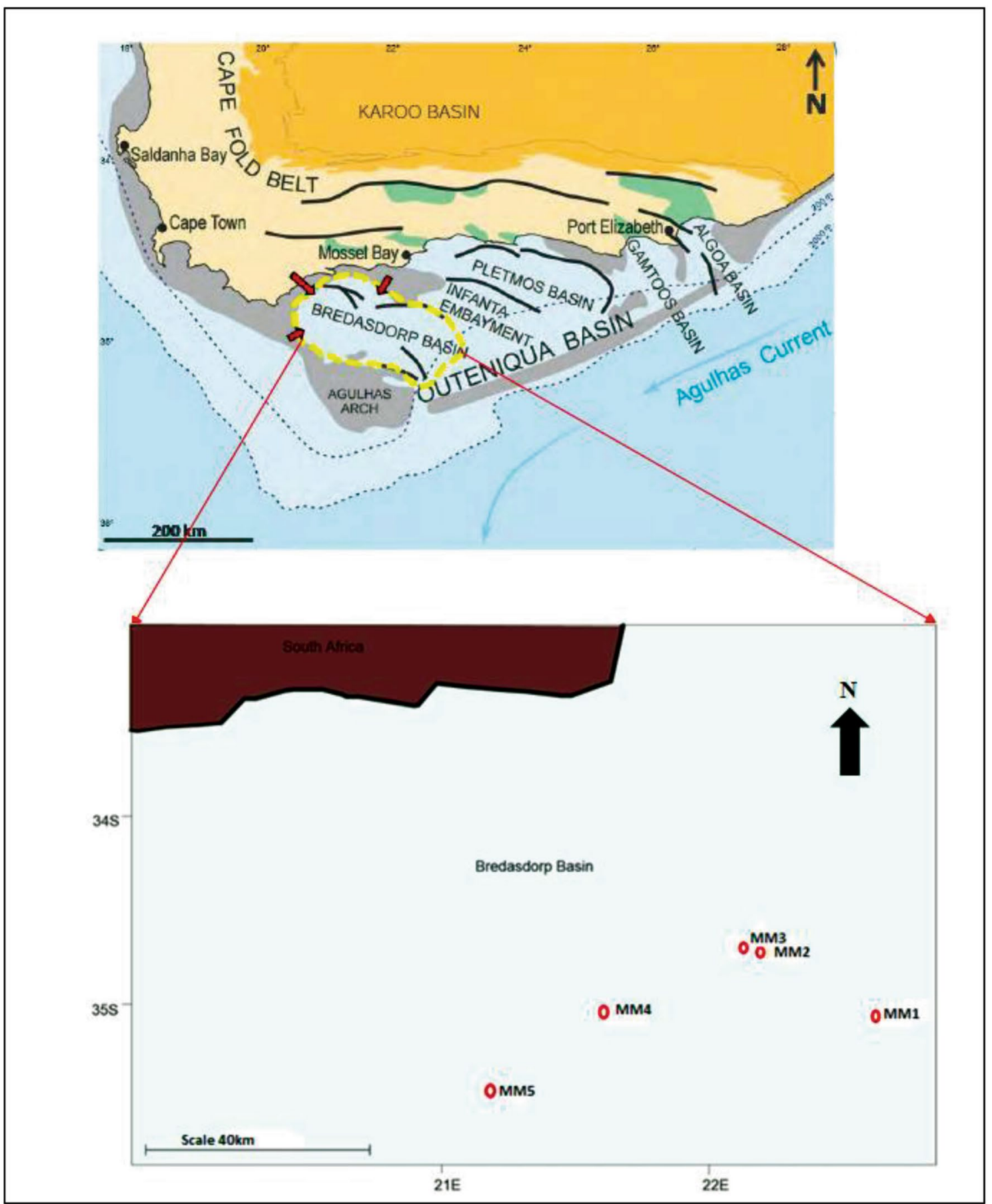

Fig. 1 Location map of the studied wells in the Bredasdorp Basin (modified after Petroleum Agency of South Africa brochure, 2004/2005) 


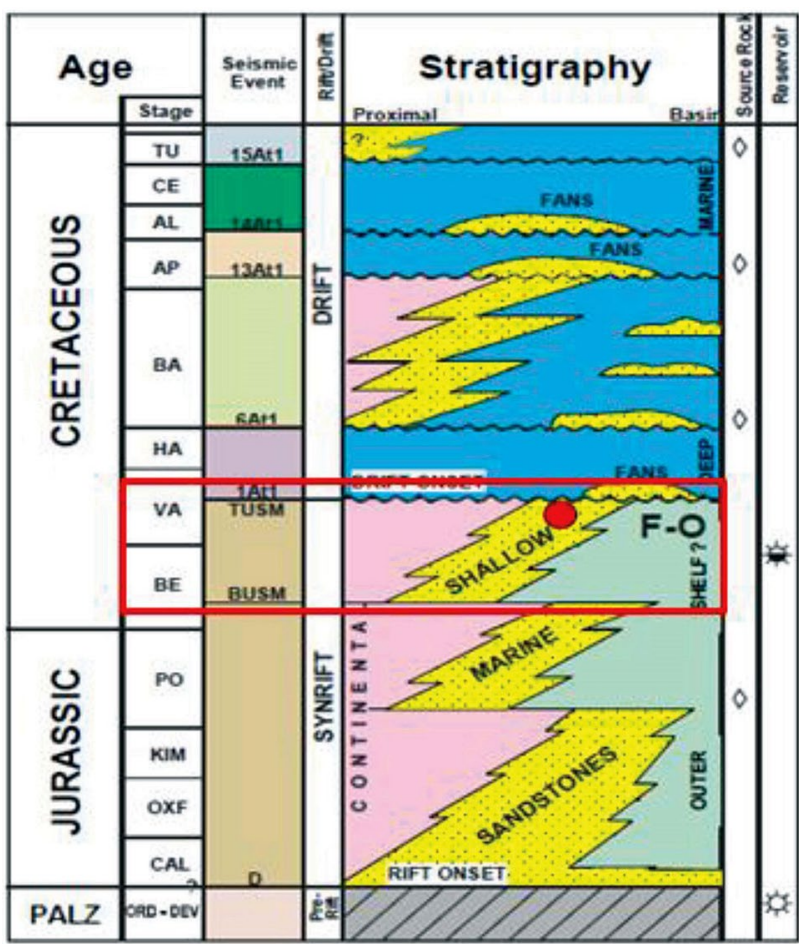

Fig. 2 No text of specified style in document. Simplified chronostratigraphy of the Bredasdorp Basin (Mudaly et al. 2009)

To produce hydrocarbon in optimum capacity, it is vital to have comprehensive knowledge about rocks and fluids in reservoir conditions. The integration of these two disciplines increases the obtained results' quality and reliability. The novelty of this study is to demonstrate how integration of petrophysics and fluid substitution can help to understand the behaviour of rock properties in response to fluid saturation changes in the Bredasdorp Basin. No similar studies have been published in the literature from the study area, and hence there is the motivation to apply this methodology in the study area.

This paper focuses on the study carried out on the upper shallow marine (USM) sandstone reservoirs of five selected wells (MM1, MM2, MM3, MM4, and MM5) in the Bredasdorp Basin, offshore South Africa. With so much attention focused on hydrocarbon exploration effort in the Bredasdorp Basin, the emphasis is increasingly laid on the quality of the potential sandstone reservoirs. The passive continental margins of South Africa are practically unexplored, although some potential is predicted and even proven by the F-O gas field offshore South Africa. The F-O gas field is classified as part of USM just below the 1AT1 unconformity. Therefore, this study investigates the potential of USM reservoirs across the formation. The integration of petrophysics and rock physics (Gassmann fluid substitution) was applied on the USM sandstone reservoirs for reservoir characterisation.

\section{Location and geology of the study area}

The study area (Fig. 1) is located within the Bredasdorp Basin, which covers roughly $18,000 \mathrm{~km}^{2}$ underneath the Indian Ocean along the south coast of South Africa, southwest of Mosselbay. The Basin is basically filled with upper Jurassic, lower Cretaceous, marine strata, post-Cretaceous, and Cenozoic unique rocks (Mudaly et al. 2009). The sandstone reservoirs of the Bredasdorp Basin are characterised by a range of stacked and amalgamated channels. The upper glauconitic sandstone developed above an unconformity after a second major marine transgression into the Bredasdorp Basin. This was trailed by an overall regressive phase that was dominated by recurrent progradation. Figure 2 shows a simplified chronostratigraphy of the Bredasdorp Basin zooming into the Upper Shallow Marine (area within the red rectangle). A detailed chronostratigraphy can be found in Mudaly et al. (2009). The western and eastern areas of the gas field region were subjected to essentially diverse subsidence rates and depositional styles during this period (Turner et al. 2000). The uniformly thick upper shallow marine unit in the east gives way to interbedded marine and non-marine intervals in the west. The discontinuous reactivation of faulting leads to exceptionally thick, stacked cycles and synsedimentary tectonic settings that were prevalently vertical in the east and predominantly tilted in the west (McMilian et al. 1997). It is understood that the reactivation of the basin margin's normal faulting at the time may have been responsible for the second marine transgression. The upper glauconitic sandstones in the eastern area of the gas field achieved a thickness of up to $237 \mathrm{~m}$. The glauconitic sandstone sequence is generally composed of blocked or recurrent, upward coarsening and cleaning units that are commonly cross-bedded. These sandstones are generally rich in quartz grains, poor in lithic, and variably glauconitic (McMilian et al. 1997).

The western gas fields consist of marine components, which are characterised by a huge abundance of coarsegrained sandstone and conglomerates, and carboniferous detritus corresponding with the disappearance of merge shell debris, compared to eastern sandstones (McMilian et al. 1997). The upper shallow marines are the best reservoirs in the gas field area and possess significant porosities and permeability.

\section{Dataset and methodology}

\section{Data collection and analysis}

This study's data were collected by Schlumberger Service Company and were provided by the Petroleum Agency of 


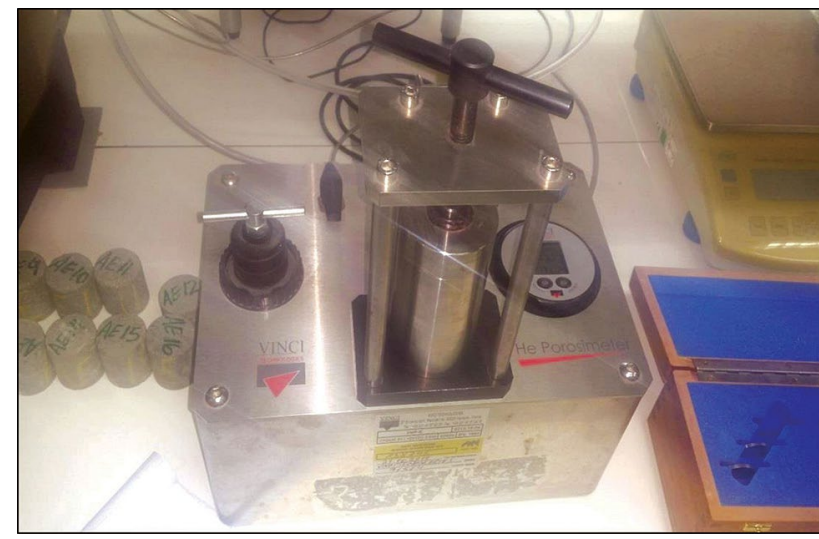

Fig. 3 Porosimeter instrument used to measure the porosity of the core plugs

South Africa (PASA). The data provided were as follows: geophysical wireline logs (LAS format), core plugs, conventional core analysis reports, and geological well completion reports. Geophysical wireline log data were carefully arranged, sorted, and prepared for easy access, and were quality controlled (QC) before being loaded into Interactive Petrophysics (IP) 4.2 software for display as log curves. The
IP software was used extensively throughout this study for interpretation and modelling. The wireline log interpretation included identifying sandstone reservoirs via gamma ray and density/neutron logs and calculating clay volume, porosity, water saturation, and permeability.

\section{Clay volume estimation}

The Vcl quantity is defined as the volume of the wetted shale per unit volume of the reservoir rock. The $\mathrm{Vcl}$ is determined from the gamma-ray $\log$ in a porous reservoir, because clay is usually more radioactive than sand or carbonate (Jensen et al. 2013).

The Vcl can be expressed as a decimal fraction or percentage. The first step required in determining the $\mathrm{Vcl}$ is to calculate the gamma-ray index (IGR). The following linear equation was used to determine the IGR:

$\mathrm{IGR}=\frac{\text { GRlog }- \text { GRmin }}{\text { GRmax }- \text { GRmin }}$

where IGR gamma-ray index and GRlog gamma-ray reading for each zone.

GRmin and GRmax are the minimum (Clean sand) and maximum gamma-ray values (shale).
Fig. 4 Porosity versus permeability multi-well cross-plot

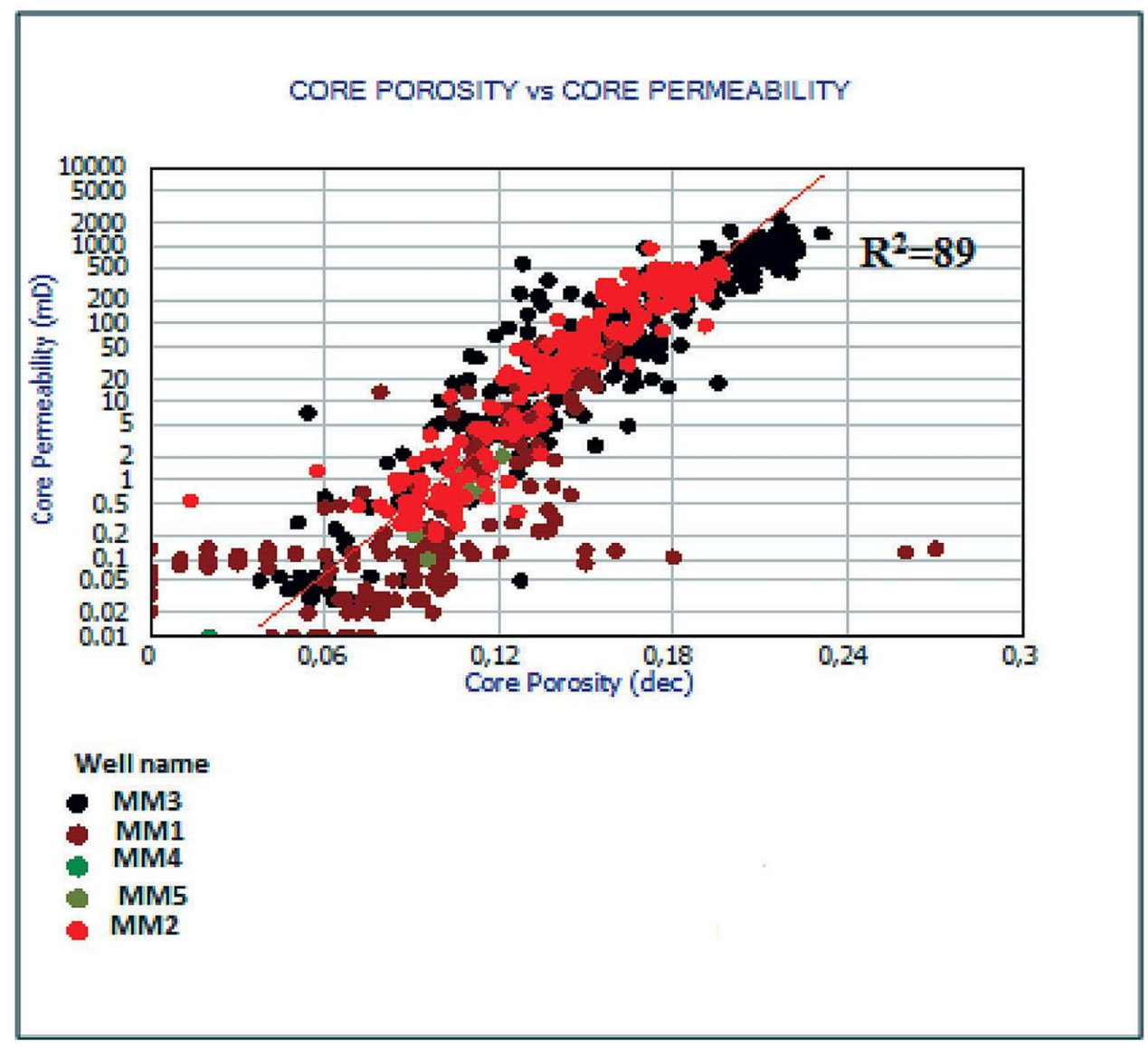


Table 1 Petrophysical parameters (gross thickness, average porosity, average water saturation, average volume of clay, and mean permeability) for the USM sands using log data from five wells

\begin{tabular}{llllrrrrr}
\hline Well name & Zone name & $\begin{array}{l}\text { Depth }(\mathrm{m}) \\
\text { Top }\end{array}$ & $\begin{array}{l}\text { Depth }(\mathrm{m}) \\
\text { Bottom }\end{array}$ & Gross $(\mathrm{m})$ & AvPhi $(\%)$ & AvSw (\%) & AvVcl (\%) & K (mD) \\
\hline MM1 & 1AT1 & 3615.5 & 3685.1 & 108.7 & 9.1 & 18.9 & 19.8 & 0.096 \\
MM4 & 1AT1 & 4081 & 4246.7 & 165.7 & 8.7 & 25.5 & 8.6 & 0.093 \\
MM5 & 1AT1 & 3149.4 & 3164.6 & 15.2 & 9.2 & 33.9 & 13.8 & 1.129 \\
MM2 & 1AT1 & 2712.2 & 2949.6 & 237.4 & 15.8 & 41.6 & 22.3 & 1.048 \\
MM3 & 1AT1 & 2610.3 & 2720.4 & 110.1 & 16.6 & 30.4 & 17.4 \\
\hline
\end{tabular}

The value of $\mathrm{Vcl}$ obtained was corrected by valid formulae in order to obtain the optimum value usable for an interpretation. Various nonlinear (correction) equations and models used to calculate the volume of shale are presented below.

Larionov (1969) for tertiary rocks

$\mathrm{Vsh}=0.083\left(2^{3.7 I G R}-1\right)$

Steiber (1970) Vsh $=\frac{\text { IGR }}{3-2 * \text { IGR }}$

Clavier $(1971) \mathrm{Vsh}=1.7-\left[3.38-(\mathrm{IGR}+0.7)^{2}\right]^{1 / 2}$

Larinov for older rocks Vsh $=0.33 *\left(2^{2 \mathrm{IGR}}-1\right)$

\section{Determining porosity from wireline logs}

Porosity is a rock's ability to store fluid within its pore spaces. Porosity was calculated from all three porosity logs (density, neutron, and sonic). The following formulae were used to calculate porosity:

\section{Density log porosity}

$\Phi=P_{\mathrm{ma}}-P_{\mathrm{b}} / P_{\mathrm{ma}}-P_{\mathrm{f}}$

where $P_{\mathrm{b}}=$ fluid density of the mud filtrate $(\mathrm{g} / \mathrm{cc})$; $P_{\mathrm{ma}}=$ matrix density $(\mathrm{g} / \mathrm{cc})$; and $P_{\mathrm{f}}=$ fluid density $(\mathrm{g} / \mathrm{cc})$; salt $\operatorname{mud}=1$; and fresh water $=1$.

\section{Neutron log porosity}

PhiN $=$ Phie $\times$ Sxo $\times$ PhiNw

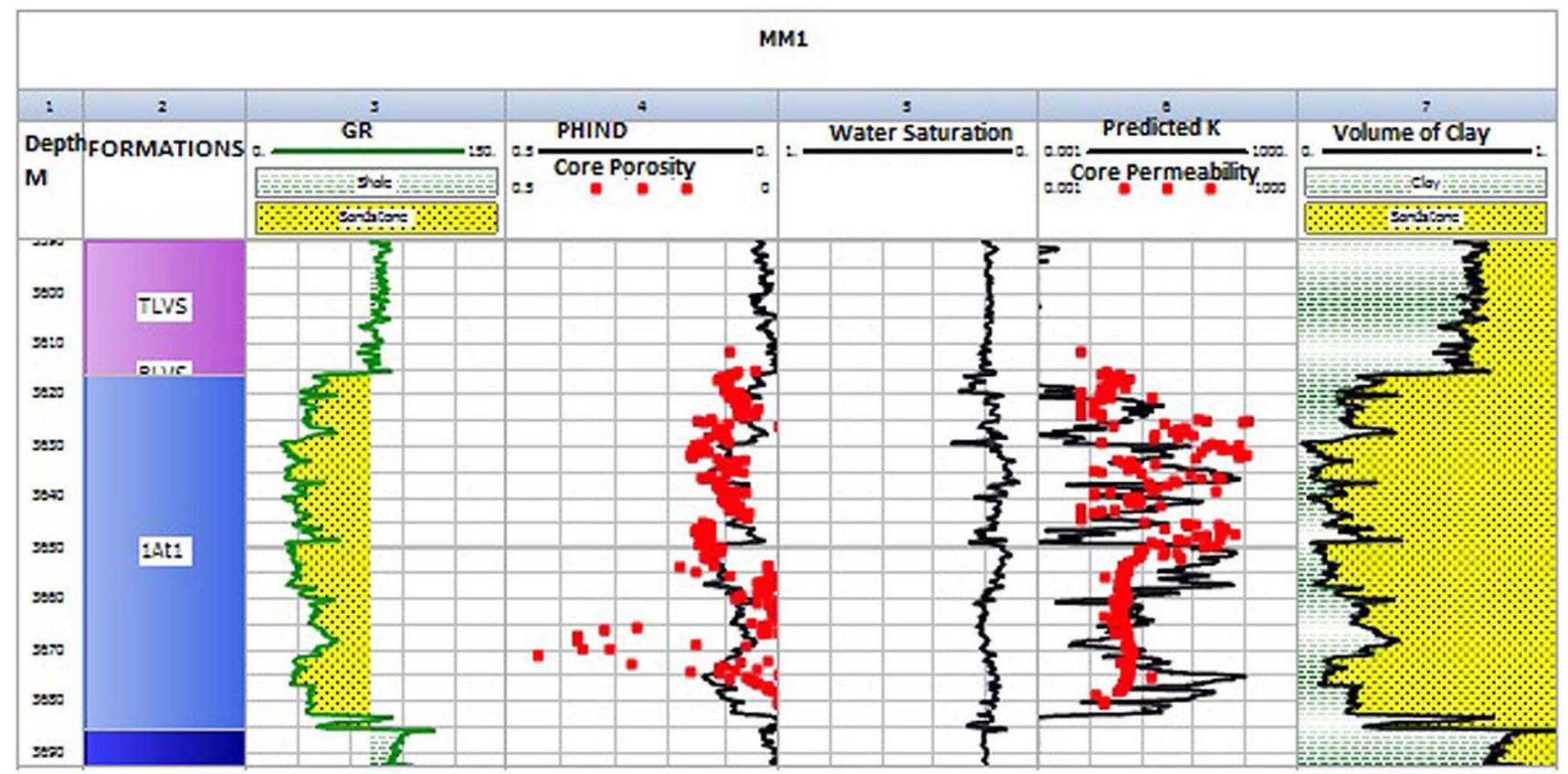

Fig. 5 Calculated reservoir results of well MM1 showing gamma ray, porosity, water saturation, permeability, and volume of clay in tracks 3, 4, 5,6 , and 7 , respectively 
where $\mathrm{PhiN}=\log$ reading; Phie $=$ effective porosity; $\mathrm{Sxo}=$ water saturation in invaded zone; and $\mathrm{PhiNw}=\log$ reading in $100 \%$ water.

\section{Sonic log porosity}

The porosity from the sonic slowness is different from that of the density or neutron tool. It reacts to primary porosity only (it does not react to fractures or vugs). The basic equation for sonic porosity is the Wyllie Time Average.

$\Phi=\Delta t l_{\mathrm{og}}-\Delta t_{\mathrm{ma}} / \Delta t_{\mathrm{f}}-\Delta t_{\mathrm{ma}}$

where $\Delta \mathrm{t}_{\mathrm{f}}=$ time taken to travel through the pore space; and $\Delta \mathrm{t}_{\mathrm{ma}}=\mathrm{time}$ taken to travel through the matrix.

The interval transit time of a formation is increased in the presence of hydrocarbons. This effect is known as the hydrocarbon effect. If this effect is not corrected, the porosity calculated from the sonic will be too high. Hilchie (1978) suggested the following empirical formulae to correct hydrocarbon effect:

$$
\begin{array}{r}
\Phi=\Phi_{\text {sonic }} \text { X0.7(Gas); and } \\
\Phi=\Phi_{\text {sonic }} \text { X } 0.9 \text { (Oil) }
\end{array}
$$

The gas empirical correction was used for this study.

\section{Using laboratory measurements to determine porosity}

The laboratory measurements for porosity were conducted on 177 core plugs. The core porosity determined from tests on the 177 plugs was measured using a helium porosimeter (Fig. 3) from the state of the art Petrophysics and Basin Analysis Laboratory (PETROLAB) at the School of Marine Geosciences at the University of Haifa in Israel. Helium porosity determines the core plug's grain volume (solid volume). The principle is based on Boyle-Mariotte's law. An Excel report template was provided to calculate the grain volume and the pore volume based on the input of the sample diameter, weight, and pressure reading on the nanometre. Nitrogen was used as the gas supply for these measurements. The core porosity measurements were calculated using the following equation:

Porosity $=\frac{\text { Pore Volume }}{\text { Bulk Volume }}$

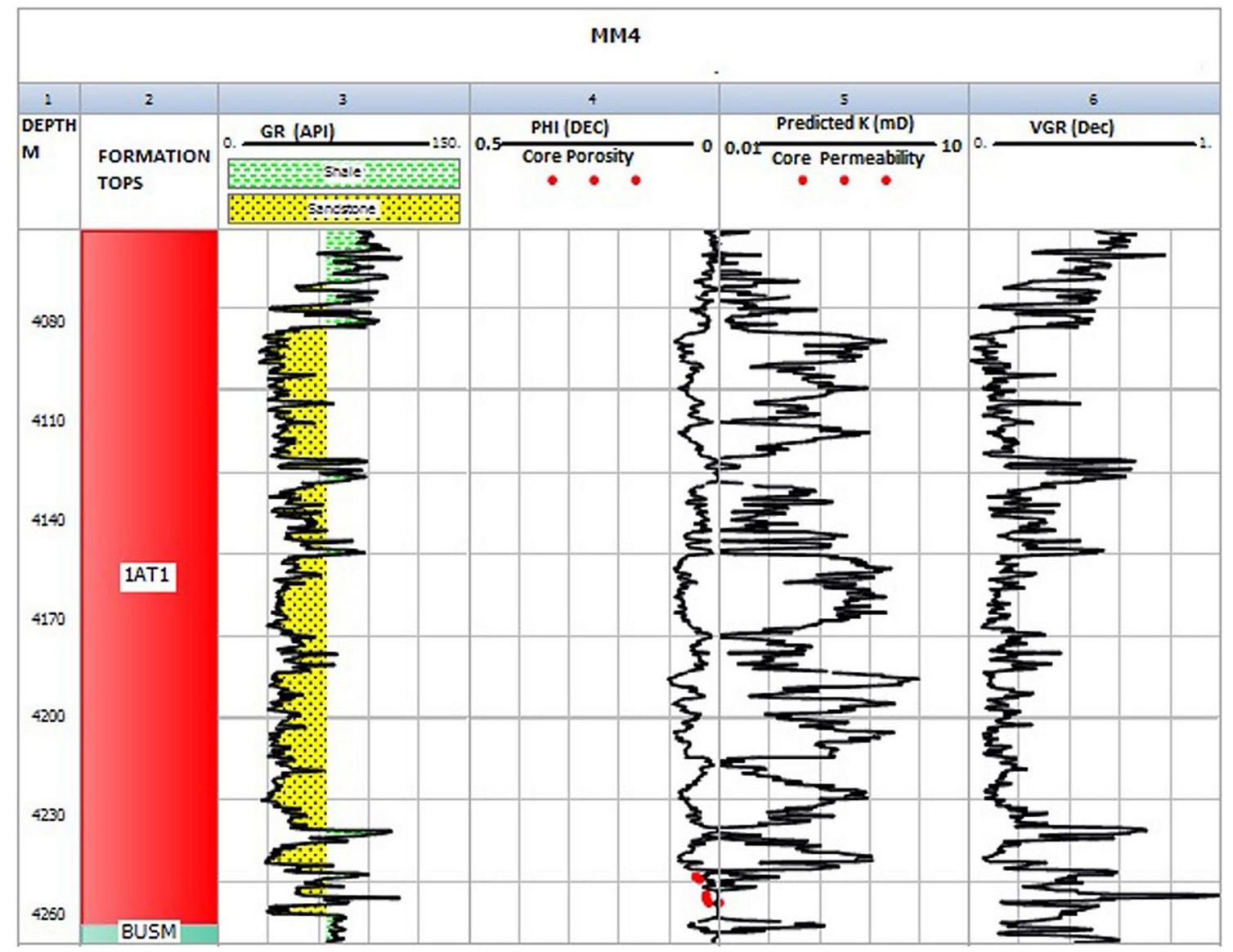

Fig. 6 Calculated reservoir results for well MM4 showing porosity, water saturation, permeability, and volume of clay in tracks 4, 5, 6, and 7, respectively 
Porosity $=\frac{\text { Bulk Volume }- \text { Grain Volume }}{\text { Bulk volume }}$

where bulk volume $=$ geometric volume calculated from diameter and length; grain volume $=$ volume of solid sample; pore volume $=$ volume of connected pores that can be invaded by gas; and porosity $=$ the ratio of pore volume to sample bulk volume.

Boyle-Mariotte's law is used to calculate grain volume and pore volume from two measures of the known mass of nitrogen. The gas is initially held in a reference pressure container and then expanded into a matrix cup (core holder).

$\frac{\text { Pref } * \text { Vref }}{\text { Tref }}=\frac{\text { Pexp } * \text { Vexp }}{\text { Texp }}$

where Pref=reference pressure (initial pressure); Vref $=$ reference volume; Tref-reference temperature; Pexp $=$ expanded pressure (final pressure); Vexp-expanded volume; and Texp=expanded absolute temperature.

During the experiment, it is assumed that the temperature will remain constant during a series of measurements. The measurements were run twice on each core sample to increase the accuracy of the results, and the average values were taken as the final measurements.

\section{Water saturation determination}

Water saturation is the ratio of water volume to pore volume (Crain 2014) Determining water saturation from log curves can be established via two models, namely clean sand (shale-free) and shaly sand models. The formation of the area of interest in this study is the shaly sand formation, and therefore the shaly sand water saturation model was used to determine the water saturation reading. The water saturation models used were the Simandoux, and the Indonesia models, since these models use effective porosity as the input porosity in water saturation models.

Simandoux (1963) proposed the following relationship:

$\mathrm{Sw}=\mathrm{aR} w / 2 \Phi m-V s h / \mathrm{Rsh}+\sqrt{(\mathrm{Vsh} / \mathrm{Rsh})} 2+4 / \mathrm{F} * \mathrm{Rw} * \mathrm{Rt}$

where $\mathrm{Sw}=$ water saturation; $a=$ equation coefficient; $\mathrm{Rw}=$ resistivity of water; Rsh = resistivity of shale; $\mathrm{Vsh}=$ volume of shale; $\mathrm{F}=$ formation resistivity factor; $\mathrm{Rt}=$ true formation resistivity from corrected deep resistivity $\log ; \Phi=$ effective porosity in fraction; and $\mathrm{m}=$ cementation exponent

The Indonesian formula was proposed in Poupon and Leveaux (1971). The relationship can be written as follows:

$1 / \sqrt{\mathrm{Rt}}=\sqrt{\Phi \mathrm{e}^{\mathrm{m}}} / \mathrm{a} * \mathrm{Rw}+\mathrm{Vcl}^{(1-\mathrm{Vcl} / 2)} / \sqrt{\mathrm{Rcl}} * \mathrm{Swn}^{2}$

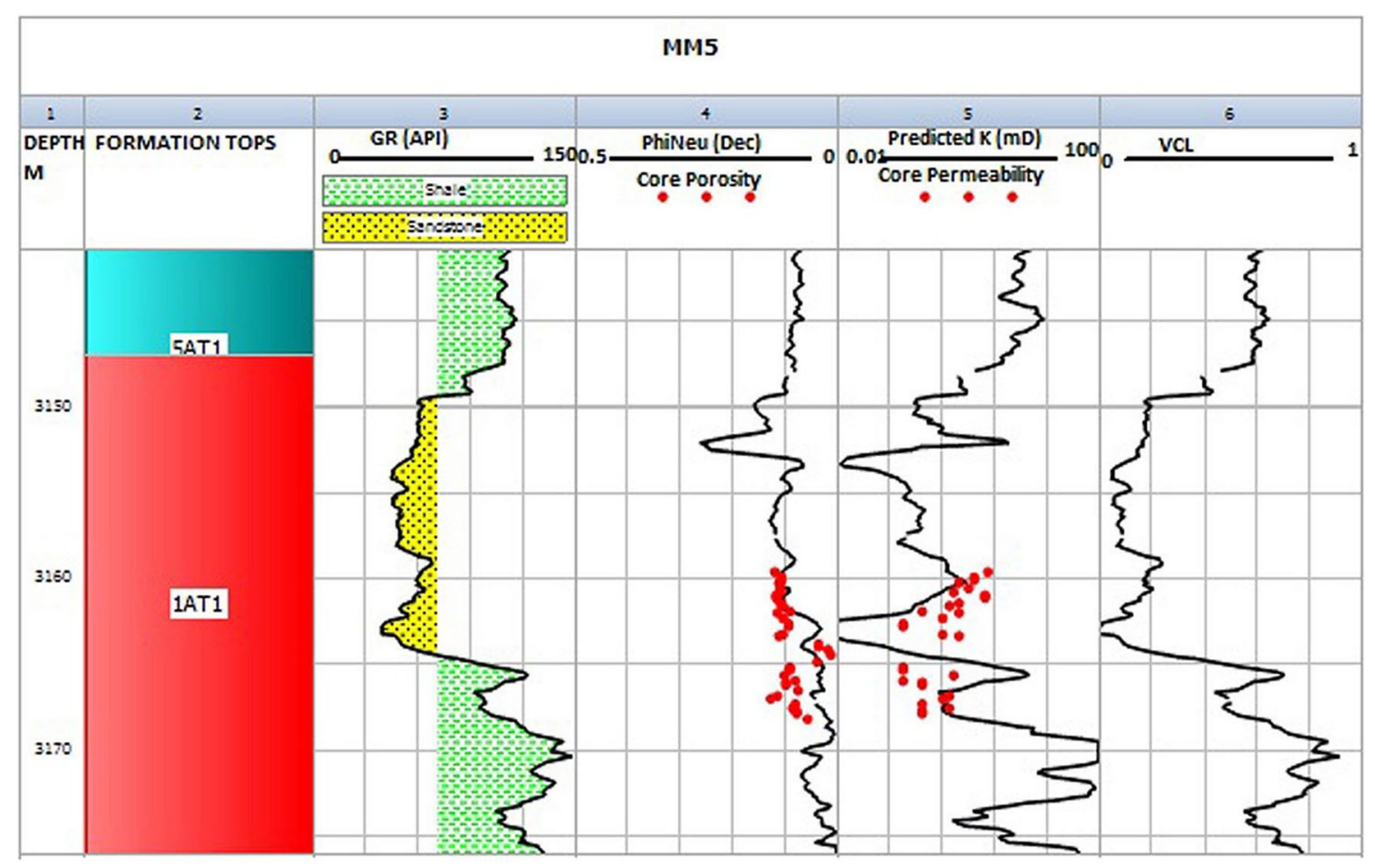

Fig. 7 Calculated reservoir results of MM5 showing porosity, water saturation, permeability, and volume of clay in track 4, 5, 6, and 7, respectively 


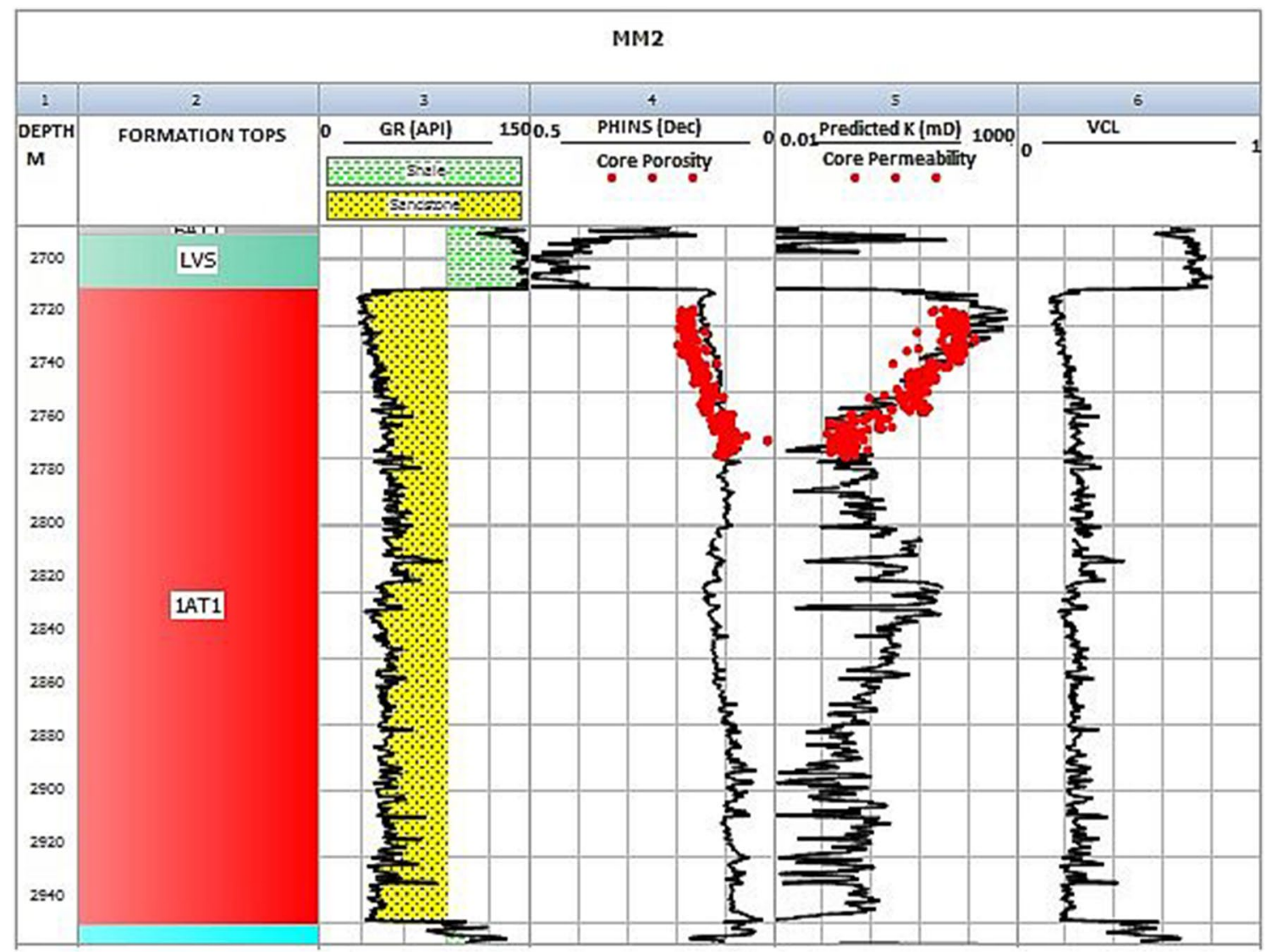

Fig. 8 Calculated reservoir results of MM2 showing porosity, water saturation, permeability, and volume of clay in tracks 4,5 , 6 , and 7 , respectively

where $\mathrm{Rt}=$ resistivity curve from deep log reading; $\mathrm{Rcl}=$ resistivity of wet clay; $\Phi \mathrm{e}=$ porosity; $\mathrm{Sw}=$ water saturation in fraction; $\mathrm{Vcl}=$ volume of clay in fraction; $\mathrm{Rw}=$ formation water resistivity; $\mathrm{m}=$ cementation exponent; $\mathrm{a}=$ tortuosity factor and $\mathrm{n}=$ saturation exponent.

\section{Permeability determination}

Permeability was predicted from the core porosity versus core permeability cross-plot (Fig. 4), using the regression equation obtained from the strength of the relationship between the two parameters. The main goal of the regression method is to obtain a regression value that is closer to 1 to make the perfect prediction. The regression value of 0.89 was obtained from the cross-plot, and that is to say that there is a 0.11 error which must be taken into account when interpreting the calculated permeability $\log$. The following equation was used:

$K=10^{(-4.73744+41.0922 * \text { Coreporosity })}$

\section{Results and discussion}

\section{Quantitative interpretation}

A quantitative approach was chosen to interpret the results of the delineated reservoirs in each well. The summary results of the computed petrophysical parameters of reservoirs are presented in Table 1.

\section{MM1 quantitative results}

The MM1 reservoir interval ranged between 3615.5 and $3685.4 \mathrm{~m}$ with a gross thickness of $69.9 \mathrm{~m}$. The average $\mathrm{Vcl}$ value of $23.3 \%$ indicated that the reservoir is a shaly sand reservoir. The average water saturation value was calculated to be $12.2 \%$. The core porosity measurements ranged from 7.42 to $12.29 \%$, with an average porosity of $10.8 \%$. Core porosity and log porosity were calibrated (Fig. 5) and indicated a good calibration between the two, except for a few anomalies near the bottom of the reservoir. 


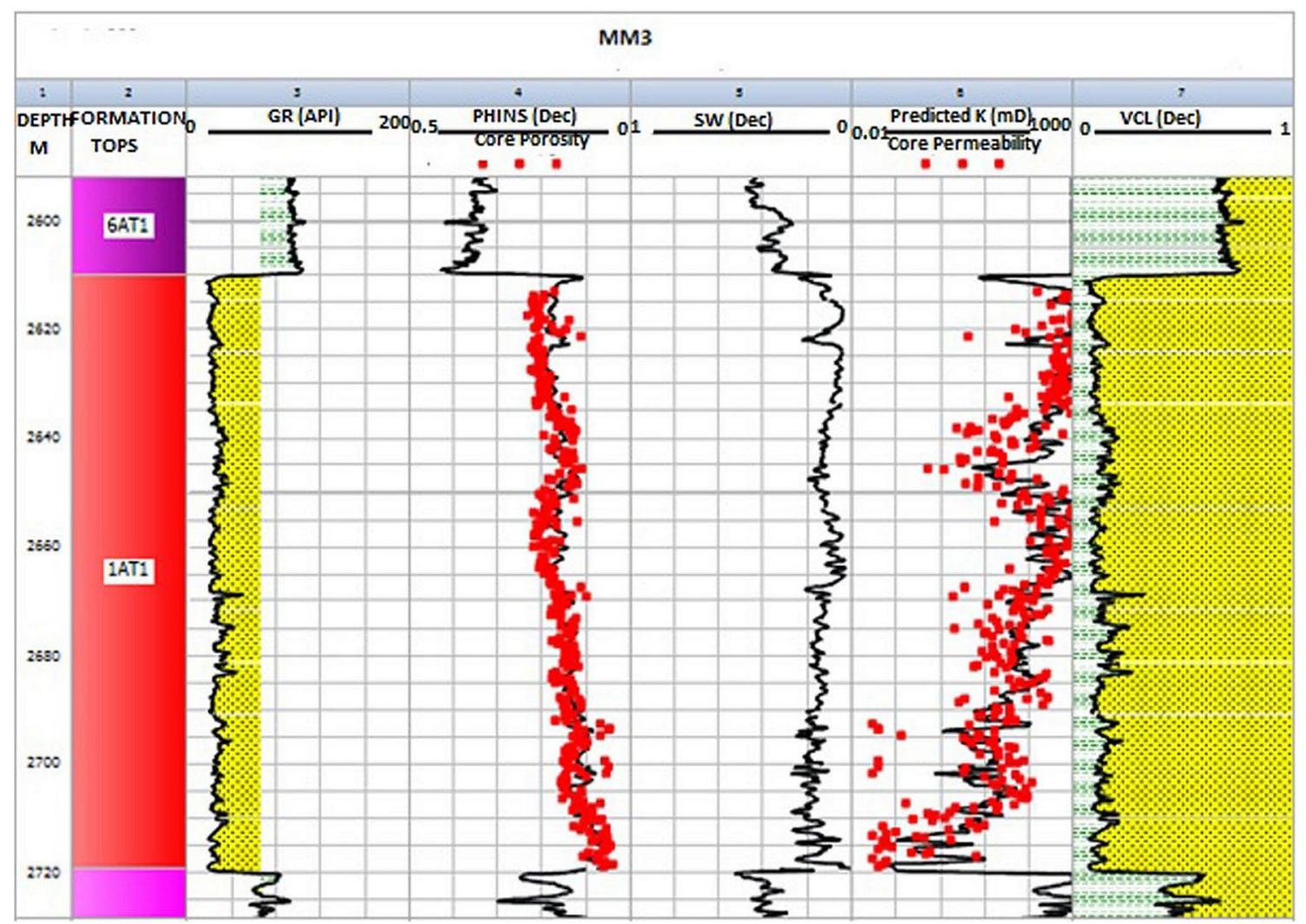

Fig. 9 Calculated reservoir results of MM3 showing porosity, water saturation, permeability, and volume of clay in tracks 4, 5, 6, and 7, respectively

\section{MM4 quantitative results}

The MM4 reservoir interval ranged between 4081 and $4246.7 \mathrm{~m}$, with a gross thickness of $167.7 \mathrm{~m}$. The average $\mathrm{Vcl}$ value of $8.6 \%$ indicated that the reservoir is more of a clean sandstone reservoir. The average water saturation value was calculated to be $25.5 \%$. Core porosity measurements ranged between 2.19 and $12.68 \%$, with an average fair porosity of $8.7 \%$. Core porosity and log porosity were calibrated (Fig. 6) and showed a good agreement.

\section{MM5 quantitative results}

The MM5 reservoir interval ranged between 3149.4 and $3164.6 \mathrm{~m}$, with a gross thickness of $15.2 \mathrm{~m}$. The average $\mathrm{Vcl}$ value of $13.8 \%$ indicated that the reservoir is a shaly sand reservoir. Core porosity measurements ranged from 3.6 to $12.7 \%$, with an average log porosity of $8.7 \%$. Core water saturation ranged from 36.6 to $67 \%$, with an average log water saturation of $33.9 \%$. The discrepancies between the log water saturation average value and the core water saturation reading may be because only eight core plugs were used for core water saturation, whereas log water saturation covered a large interval, with a reading recorded at every $15 \mathrm{~cm}$. The core measurements of porosity and water saturation were calibrated (Fig. 7). Porosity and permeability showed a fairly poor agreement at some depths, and water saturation showed good calibration.

\section{MM2 quantitative results}

The MM2 reservoir intervals ranged between 2721.2 and $2949.6 \mathrm{~m}$, with a gross thickness of $237.4 \mathrm{~m}$. The average $\mathrm{Vcl}$ value of $22.3 \%$ indicated that the reservoir is a shaly sand reservoir. The core porosity measurements ranged from 19.43 to $27.65 \%$, with an average log porosity of $15.8 \%$. Core water saturation ranged between 30 and $71 \%$, with an average log water saturation of $41.6 \%$. Core porosity, core water saturation, and core permeability were calibrated with log measurements (Fig. 8). Porosity and permeability results showed good calibration, whereas water saturation showed a fairly poor calibration at the top of the reservoir. 
Fig. 10 Example of shear velocity quality control (QC) crossplot showing the relationship between $\mathrm{Vp}$ and $\mathrm{Vs}$ calculated using the Greenberg and Castagna (1992) relationship model in the MM3 well

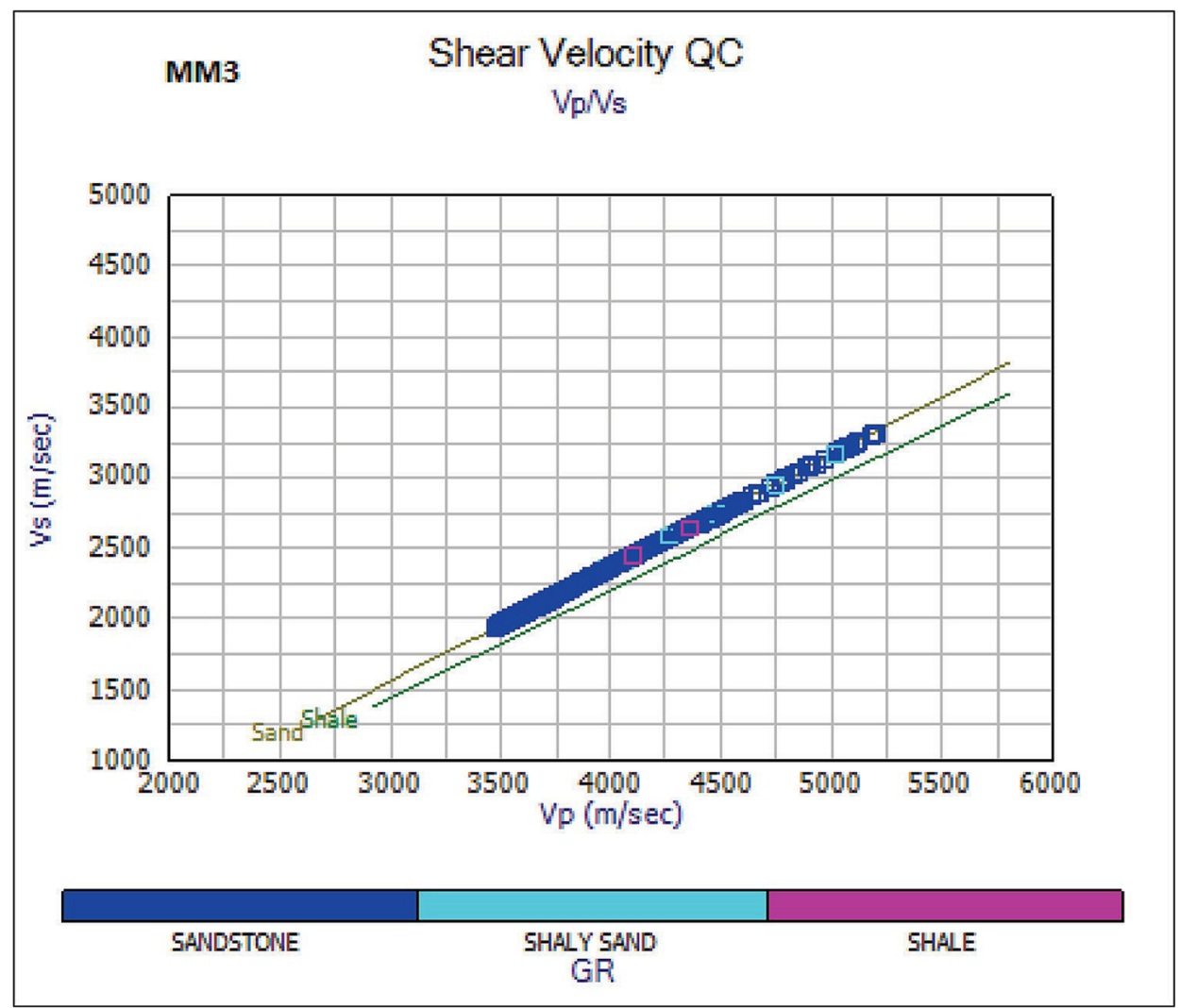

\section{MM3 quantitative results}

The MM3 reservoir interval ranged from 2610.3 to $2720.4 \mathrm{~m}$, with a gross thickness of $110.1 \mathrm{~m}$. The average $\mathrm{Vcl}$ value of $17.4 \%$ indicated that the reservoir is a shaky sand reservoir. The average water saturation value was calculated to be $30.4 \%$. Core porosity measurements ranged from 11.71 to $22.91 \%$, with an average porosity of $16.6 \%$. Core porosity and core permeability were calibrated with the $\log$ results and showed a very good agreement between the two (Fig. 9).

\section{Gassmann fluid substitution modelling}

Fluid substitution is an important part of seismic rock physics because it provides a valuable tool for modelling various pore fluid scenarios, which might explain the changes in amplitude variation with offset (AVO) (Smith et al. 2003). The most common method used in performing fluid substitution is based on Gassmann's (1951) work. His method relates the saturated bulk modulus of the rock to its porosity, the bulk modulus of the porous rock frame, the bulk modulus of the mineral matrix, and the bulk modulus of the pore-filling fluids (Gassmann 1951). This method depends on changing the type of pore fluids in the reservoir intervals to study the AVO response caused by the new fluid type
(El-Bahiry et al. 2017). Gassmann's relation methods reflect variations in compressional velocity $(\mathrm{Vp})$ and shear velocity (Vs) velocities with changes in fluid saturations that have simple input parameters. The primary inputs are $\mathrm{Vp}, \mathrm{Vs}$, and bulk density, while the matrix bulk modulus (Ko), frame or dry rock modulus $\left(\mathrm{K}^{*}\right)$, porosity, and the rock shear modulus remain constant during the substitution modelling (Smith et al. 2003; Khan and Rehman 2018).

The Gassmann equation assumes that the rock is homogeneous and isotropic and that the pore system must be connected and fluid must be moveable (Smith et al. 2003). Reliable results are often obtained for clean sand with high effective porosity. Unreliable results often occur in lowporosity or shaley-sands or to carbonate rock. The application of Gassmann equation for the USM reservoirs was relevant because the reservoirs showed a fairly low volume of shale between 8.6 and $22.3 \%$, and this low volume of clay qualifies the reservoirs to be considered as possibly cleaner sandstone. The petrophysical analysis indicated that the reservoirs have good pore interconnectivity (average effective porosity $=16.6 \%$ and average permeability $=151 \mathrm{mD}$ ). The Gassmann fluid substitution was performed on the shallow marine sandstone reservoirs in the five studied wells to model the seismic velocity and density at different water saturation levels (Figs. 11, 12, 13, 14, 15, 16). Before performing the fluid substitution modelling using the Gassmann 
Table 2 Gassmann fluid substitution results of MM1

\begin{tabular}{|c|c|c|c|c|}
\hline MM1 & Brine & & Oil & Gas \\
\hline \multicolumn{5}{|l|}{ Fluid properties } \\
\hline \multicolumn{5}{|l|}{ Flushed zone } \\
\hline Density $(\mathrm{gm} / \mathrm{cc})$ & \multicolumn{2}{|l|}{0.9527} & 0.6454 & 0.1605 \\
\hline Bulk modulus (Gpa) & \multicolumn{2}{|l|}{2.3063} & 0.3249 & 0.0571 \\
\hline Velocity $(\mathrm{m} / \mathrm{s})$ & \multicolumn{2}{|l|}{1555.9} & 709.5 & 596.2 \\
\hline \multicolumn{5}{|l|}{ Reservoir zone } \\
\hline Density $(\mathrm{gm} / \mathrm{cc})$ & \multicolumn{2}{|l|}{0.9527} & 0.6454 & 0.1605 \\
\hline Bulk modulus (Gpa) & \multicolumn{2}{|l|}{2.3063} & 0.3249 & 0.0571 \\
\hline Velocity $(\mathrm{m} / \mathrm{s})$ & \multicolumn{2}{|l|}{1555.9} & 709.5 & 596.2 \\
\hline \multicolumn{5}{|l|}{ Matrix properties } \\
\hline & \multicolumn{2}{|l|}{ Quartz } & \multicolumn{2}{|l|}{ Wet clay } \\
\hline \multicolumn{5}{|l|}{ Mineral name } \\
\hline Density $(\mathrm{gm} / \mathrm{cc})$ & \multicolumn{2}{|l|}{2.65} & \multicolumn{2}{|l|}{2.6} \\
\hline Modulus (Gpa) & \multicolumn{2}{|l|}{37} & \multicolumn{2}{|l|}{21} \\
\hline Velocity $(\mathrm{m} / \mathrm{s})$ & \multicolumn{2}{|l|}{6050} & \multicolumn{2}{|l|}{3140} \\
\hline \multicolumn{5}{|c|}{ Average Gassmann results } \\
\hline \multicolumn{5}{|l|}{ Log inputs } \\
\hline \multicolumn{5}{|c|}{ Data from interval: $3615.5-3685.4$} \\
\hline & \multicolumn{3}{|c|}{ Log value } & Value used \\
\hline $\mathrm{Vp}(\mathrm{m} / \mathrm{s})$ & \multicolumn{3}{|c|}{4127} & 4127 \\
\hline Vs $(\mathrm{m} / \mathrm{s})$ & \multicolumn{3}{|c|}{2487} & 2487 \\
\hline $\mathrm{Vp} / \mathrm{Vs}$ ratio & \multicolumn{3}{|c|}{1.659} & 1.659 \\
\hline Poison ratio & \multicolumn{3}{|c|}{0.215} & 0.215 \\
\hline Density (gm/cc) & & 2.501 & & 2.501 \\
\hline Quartz (dec) & & 1 & & 1 \\
\hline Wet clay (dec) & & 0 & & 0 \\
\hline Porosity (dec) & & 0.076 & & 0.073 \\
\hline $\mathrm{Sw}(\mathrm{dec})$ & & 0.169 & & 0.169 \\
\hline Sxo (dec) & & 0.556 & & 0.556 \\
\hline $\begin{array}{l}\text { Flushed zone fluid mixt } \\
\text { Fluid mixing law is } 3\end{array}$ & & & & \\
\hline Fluid properties & & & & \\
\hline Fluid density $(\mathrm{gm} / \mathrm{cc})$ & & 0.601 & & \\
\hline Fluid modulus (Gpa) & & $0 . .4435$ & & \\
\hline Fluid velocity (m/s) & & 859 & & \\
\hline Dry rock properties & & & & \\
\hline Bulk modulus (Gpa) & & 20.866 & & \\
\hline Shear modulus (Gpa) & & 15.468 & & \\
\hline Poison ratio & & 0.203 & & \\
\hline Modulus ratio $(\mathrm{K} / \mathrm{u})$ & & 1.349 & & \\
\hline
\end{tabular}


Table 3 Gassmann fluid substitution results of well MM5

\begin{tabular}{|c|c|c|c|}
\hline MM5 & Brine & Oil & Gas \\
\hline \multicolumn{4}{|l|}{ Fluid properties } \\
\hline \multicolumn{4}{|l|}{ Flushed zone } \\
\hline Density (gm/cc) & 0.9734 & 0.5961 & 0.2448 \\
\hline Bulk modulus (Gpa) & 2.5625 & 0.4534 & 0.1152 \\
\hline Velocity (m/s) & 1622.5 & 872.2 & 686.1 \\
\hline \multicolumn{4}{|l|}{ Reservoir zone } \\
\hline Density (gm/cc) & 0.9734 & 0.5961 & 0.2448 \\
\hline Bulk modulus (Gpa) & 2.5625 & 0.4534 & 0.1152 \\
\hline Velocity $(\mathrm{m} / \mathrm{s})$ & 1622.5 & 872.2 & 686.1 \\
\hline \multicolumn{4}{|l|}{ Matrix properties } \\
\hline Mineral name & Quartz & Wet clay & \\
\hline Density (gm/cc) & 2.65 & 2.6 & \\
\hline Modulus (Gpa) & 37 & 21 & \\
\hline Velocity (m/s) & 6050 & 3140 & \\
\hline
\end{tabular}

Average Gassmann results

Log inputs

Data from interval: 3149.4-3164.6

\begin{tabular}{|c|c|c|}
\hline & Log value & Value used \\
\hline $\mathrm{Vp}(\mathrm{m} / \mathrm{s})$ & 4433 & 4433 \\
\hline Vs $(\mathrm{m} / \mathrm{s})$ & 2709 & 2709 \\
\hline $\mathrm{Vp} / \mathrm{Vs}$ ratio & 1.636 & 1.636 \\
\hline Poison ratio & 0.202 & 0.202 \\
\hline Density (gm/cc) & 2.566 & 2.566 \\
\hline Quartz (dec) & 1 & 1 \\
\hline Wet clay (dec) & 0 & 0 \\
\hline Porosity (dec) & 0.11 & 0.044 \\
\hline Sw $(\operatorname{dec})$ & 0.494 & 0.494 \\
\hline Sxo (dec) & 0.364 & 0.364 \\
\hline \multicolumn{3}{|c|}{ Flushed zone fluid mixture is oil/brine } \\
\hline \multicolumn{3}{|l|}{ Fluid mixing law is 3} \\
\hline \multicolumn{3}{|l|}{ Fluid properties } \\
\hline Fluid density (gm/cc) & 0.733 & \\
\hline Fluid modulus (Gpa) & 0.5551 & \\
\hline Fluid velocity $(\mathrm{m} / \mathrm{s})$ & 870 & \\
\hline \multicolumn{3}{|l|}{ Dry rock properties } \\
\hline Bulk modulus (Gpa) & 23.875 & \\
\hline Shear modulus (Gpa) & 18.53 & \\
\hline Poison ratio & 0.188 & \\
\hline Modulus ratio (K/u) & 1.268 & \\
\hline
\end{tabular}

equation, the following input parameters were determined: (1) the porosity of the rock; (2) the bulk modulus of the pore fluids; (3) the Ko; and (4) the bulk modulus of the porous rock frame devoid of any fluids $\left(\mathrm{K}^{*}\right)$. All these parameters were determined from the wireline log data analysis, while porosity was determined from both the wireline log data, and routinely from the core data. The Gassmann equation is presented as:
$K_{\mathrm{sat}}=K^{*}+\frac{\left(1-\frac{K^{*}}{K_{\mathrm{o}}}\right)^{2}}{\frac{\phi}{K_{\mathrm{fl}}}+\frac{(1-\phi)}{K_{\mathrm{o}}}-\frac{K^{*}}{K_{\mathrm{o}}^{2}}}$,

The Gassmann equation uses rock frame properties to calculate the effects of fluid substitution on seismic properties. 
Table 4 Gassmann fluid substitution results of well MM4

\begin{tabular}{|c|c|c|c|c|}
\hline MM4 & Brine & & Oil & Gas \\
\hline \multicolumn{5}{|l|}{ Fluid properties } \\
\hline \multicolumn{5}{|l|}{ Flushed zone } \\
\hline Density $(\mathrm{gm} / \mathrm{cc})$ & 0.9496 & & 0.6276 & 0.1514 \\
\hline Bulk modulus (Gpa) & 2.2513 & & 0.2708 & 0.055 \\
\hline Velocity $(\mathrm{m} / \mathrm{s})$ & 1539.7 & & 656.9 & 602.5 \\
\hline \multicolumn{5}{|l|}{ Reservoir zone } \\
\hline Density $(\mathrm{gm} / \mathrm{cc})$ & 0.9546 & & 0.5976 & 0.2017 \\
\hline Bulk modulus (Gpa) & 2.3465 & & 0.3352 & 0.0856 \\
\hline Velocity $(\mathrm{m} / \mathrm{s})$ & 1567.9 & & 748.9 & 651.5 \\
\hline \multicolumn{5}{|l|}{ Matrix properties } \\
\hline Mineral name & Quartz & & Wet clay & \\
\hline Density $(\mathrm{gm} / \mathrm{cc})$ & 2.65 & & 2.6 & \\
\hline Modulus (Gpa) & 37 & & 21 & \\
\hline Velocity $(\mathrm{m} / \mathrm{s})$ & 6050 & & 3140 & \\
\hline \multicolumn{5}{|l|}{ Average Gassmann results } \\
\hline \multicolumn{5}{|l|}{ Log inputs } \\
\hline \multicolumn{5}{|c|}{ Data from interval: $4081-4256.7$} \\
\hline & & Log value & & Value used \\
\hline $\mathrm{Vp}(\mathrm{m} / \mathrm{s})$ & & 4598 & & 4598 \\
\hline $\mathrm{Vs}(\mathrm{m} / \mathrm{s})$ & & 2842 & & 2842 \\
\hline $\mathrm{Vp} / \mathrm{Vs}$ ratio & & 1.618 & & 1.618 \\
\hline Poison ratio & & 0.191 & & 0.191 \\
\hline Density $(\mathrm{gm} / \mathrm{cc})$ & & 2.581 & & 2.581 \\
\hline Quartz (dec) & & 1 & & 1 \\
\hline Wet clay (dec) & & 0 & & 0 \\
\hline Porosity (dec) & & 0.05 & & 0.036 \\
\hline Sw $(\mathrm{dec})$ & & 0.2723 & & 0.273 \\
\hline Sxo $(\mathrm{dec})$ & & 0.729 & & 0.729 \\
\hline \multicolumn{5}{|c|}{ Flushed zone fluid mixture is gas/brine } \\
\hline \multicolumn{5}{|l|}{ Fluid mixing law is 3} \\
\hline \multicolumn{5}{|l|}{ Fluid properties } \\
\hline Fluid density $(\mathrm{gm} / \mathrm{cc})$ & & 0.733 & & \\
\hline Fluid modulus (Gpa) & & 0.9044 & & \\
\hline Fluid velocity (m/s) & & 1111 & & \\
\hline \multicolumn{5}{|l|}{ Dry rock properties } \\
\hline Bulk modulus (Gpa) & & 23.339 & & \\
\hline Shear modulus (Gpa) & & 20.849 & & \\
\hline Poison ratio & & 0.167 & & \\
\hline Modulus ratio (K/u) & & 1.167 & & \\
\hline
\end{tabular}


Table 5 Gassmann fluid substitution results of well MM3

\begin{tabular}{|c|c|c|c|c|}
\hline MM3 & Brine & & Oil & Gas \\
\hline \multicolumn{5}{|l|}{ Fluid properties } \\
\hline \multicolumn{5}{|l|}{ Flushed zone } \\
\hline Density (gm/cc) & 0.9903 & & 0.6206 & 0.223 \\
\hline Bulk modulus (Gpa) & 2.6441 & & 0.4071 & 0.0848 \\
\hline Velocity $(\mathrm{m} / \mathrm{s})$ & 1634 & & 809.9 & 616.6 \\
\hline \multicolumn{5}{|l|}{ Reservoir zone } \\
\hline Density (gm/cc) & 0.9924 & & 0.6202 & 0.2253 \\
\hline Bulk modulus (Gpa) & 2.6581 & & 0.4103 & 0.0856 \\
\hline Velocity $(\mathrm{m} / \mathrm{s})$ & 1636.6 & & 813.4 & 616.4 \\
\hline \multicolumn{5}{|l|}{ Matrix properties } \\
\hline Mineral name & Quartz & & Wet clay & \\
\hline Density (gm/cc) & 2.65 & & 2.6 & \\
\hline Modulus (Gpa) & 37 & & 21 & \\
\hline Velocity (m/s) & 6050 & & 3140 & \\
\hline \multicolumn{5}{|l|}{ Average Gassmann results } \\
\hline \multicolumn{5}{|l|}{ Log inputs } \\
\hline \multicolumn{5}{|c|}{ Data from interval: $2610.3-2720.1$} \\
\hline & & Log value & & Value used \\
\hline $\mathrm{Vp}(\mathrm{m} / \mathrm{s})$ & & 4034 & & 4034 \\
\hline Vs $(\mathrm{m} / \mathrm{s})$ & & 2388 & & 2388 \\
\hline $\mathrm{Vp} / \mathrm{Vs}$ ratio & & 1.689 & & 1.689 \\
\hline Poison ratio & & 0.23 & & 0.23 \\
\hline Density (gm/cc) & & 2.426 & & 2.426 \\
\hline Quartz (dec) & & 1 & & 1 \\
\hline Wet clay (dec) & & 0 & & 0 \\
\hline Porosity (dec) & & 0.142 & & 0.104 \\
\hline Sw (dec) & & 0.122 & & 0.122 \\
\hline Sxo $(\mathrm{dec})$ & & 0.362 & & 0.362 \\
\hline \multicolumn{5}{|c|}{ Flushed zone fluid mixture is gas/brine } \\
\hline \multicolumn{5}{|c|}{ Fluid mixing law is 3} \\
\hline \multicolumn{5}{|l|}{ Fluid properties } \\
\hline Fluid density (gm/cc) & & 0.501 & & \\
\hline Fluid modulus (Gpa) & & 0.2065 & & \\
\hline Fluid velocity (m/s) & & 642 & & \\
\hline \multicolumn{5}{|l|}{ Dry rock properties } \\
\hline Bulk modulus (Gpa) & & 20.655 & & \\
\hline Shear modulus (Gpa) & & 13.838 & & \\
\hline Poison ratio & & 0.226 & & \\
\hline Modulus ratio (K/u) & & 1.493 & & \\
\hline
\end{tabular}


Table 6 Gassmann fluid substitution results of well MM2

\begin{tabular}{|c|c|c|c|c|}
\hline MM2 & Brine & & Oil & Gas \\
\hline \multicolumn{5}{|l|}{ Fluid properties } \\
\hline \multicolumn{5}{|l|}{ Flushed zone } \\
\hline Density (gm/cc) & 0.9828 & & 0.6446 & 0.1851 \\
\hline Bulk modulus (Gpa) & 2.5546 & & 0.3953 & 0.0613 \\
\hline Velocity $(\mathrm{m} / \mathrm{s})$ & 1612 & & 783.1 & 572.4 \\
\hline \multicolumn{5}{|l|}{ Reservoir zone } \\
\hline Density (gm/cc) & 0.9828 & & 0.6446 & 0.1851 \\
\hline Bulk modulus (Gpa) & 2.5546 & & 0.3953 & 0.0613 \\
\hline Velocity $(\mathrm{m} / \mathrm{s})$ & 1612 & & 783.1 & 572.4 \\
\hline \multicolumn{5}{|l|}{ Matrix properties } \\
\hline Mineral name & Quartz & & Wet clay & \\
\hline Density (gm/cc) & 2.65 & & 2.6 & \\
\hline Modulus (Gpa) & 37 & & 21 & \\
\hline Velocity $(\mathrm{m} / \mathrm{s})$ & 6050 & & 3140 & \\
\hline \multicolumn{5}{|l|}{ Average Gassmann results } \\
\hline \multicolumn{5}{|l|}{ Log inputs } \\
\hline \multicolumn{5}{|c|}{ Data from interval: $2712.2-2949.8$} \\
\hline & & Log value & & Value used \\
\hline $\mathrm{Vp}(\mathrm{m} / \mathrm{s})$ & & 4335 & & 4335 \\
\hline Vs $(\mathrm{m} / \mathrm{s})$ & & 2630 & & 2630 \\
\hline $\mathrm{Vp} / \mathrm{Vs}$ ratio & & 1.648 & & 1.648 \\
\hline Poison ratio & & 0.209 & & 0.209 \\
\hline Density (gm/cc) & & 2.455 & & 2.455 \\
\hline Quartz (dec) & & 1 & & 1 \\
\hline Wet clay (dec) & & 0 & & 0 \\
\hline Porosity (dec) & & 0.104 & & 0.098 \\
\hline $\mathrm{Sw}(\mathrm{dec})$ & & 0.512 & & 0.512 \\
\hline Sxo (dec) & & 0.593 & & 0.593 \\
\hline \multicolumn{5}{|c|}{ Flushed zone fluid mixture is gas/brine } \\
\hline \multicolumn{5}{|l|}{ Fluid mixing law is 3} \\
\hline \multicolumn{5}{|l|}{ Fluid properties } \\
\hline Fluid density (gm/cc) & & 0.658 & & \\
\hline Fluid modulus (Gpa) & & 0.582 & & \\
\hline Fluid velocity (m/s) & & 940 & & \\
\hline \multicolumn{5}{|l|}{ Dry rock properties } \\
\hline Bulk modulus (Gpa) & & 22.64 & & \\
\hline Shear modulus (Gpa) & & 16.989 & & \\
\hline Poison ratio & & 0.2 & & \\
\hline Modulus ratio (K/u) & & 1.333 & & \\
\hline
\end{tabular}




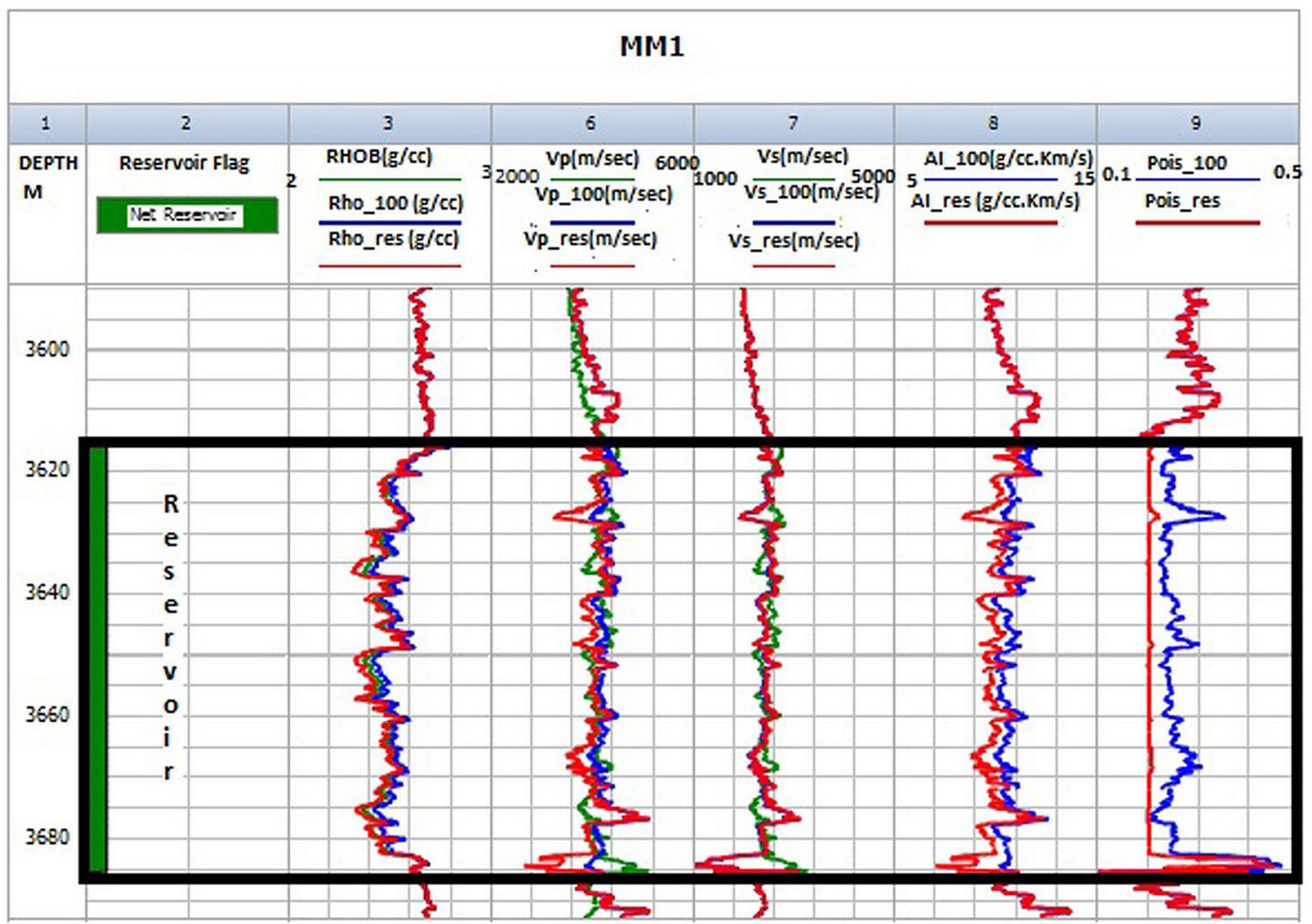

Fig. 11 Elastic impedance logs for MM1 well showing the calculated parameters (Vp, Vs, Al, and poison ratio) at different saturation levels (100\% water saturation and gas) in the reservoir intervals

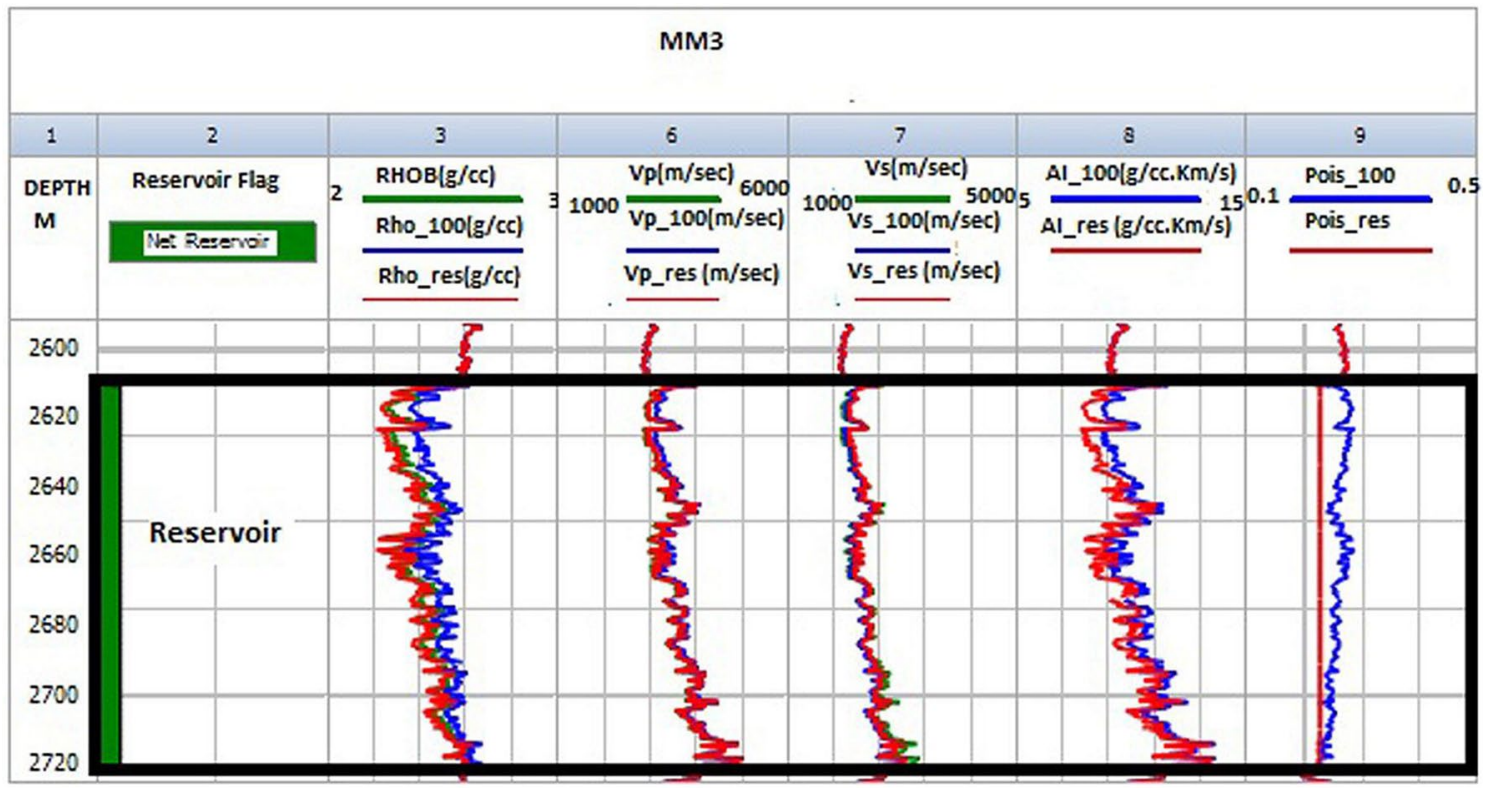

Fig. 12 Elastic impedance logs for MM3 well showing the calculated parameters (Vp, Vs, Al, and poison ratio) at different saturation levels (100\% water saturation and gas) in the reservoir intervals 


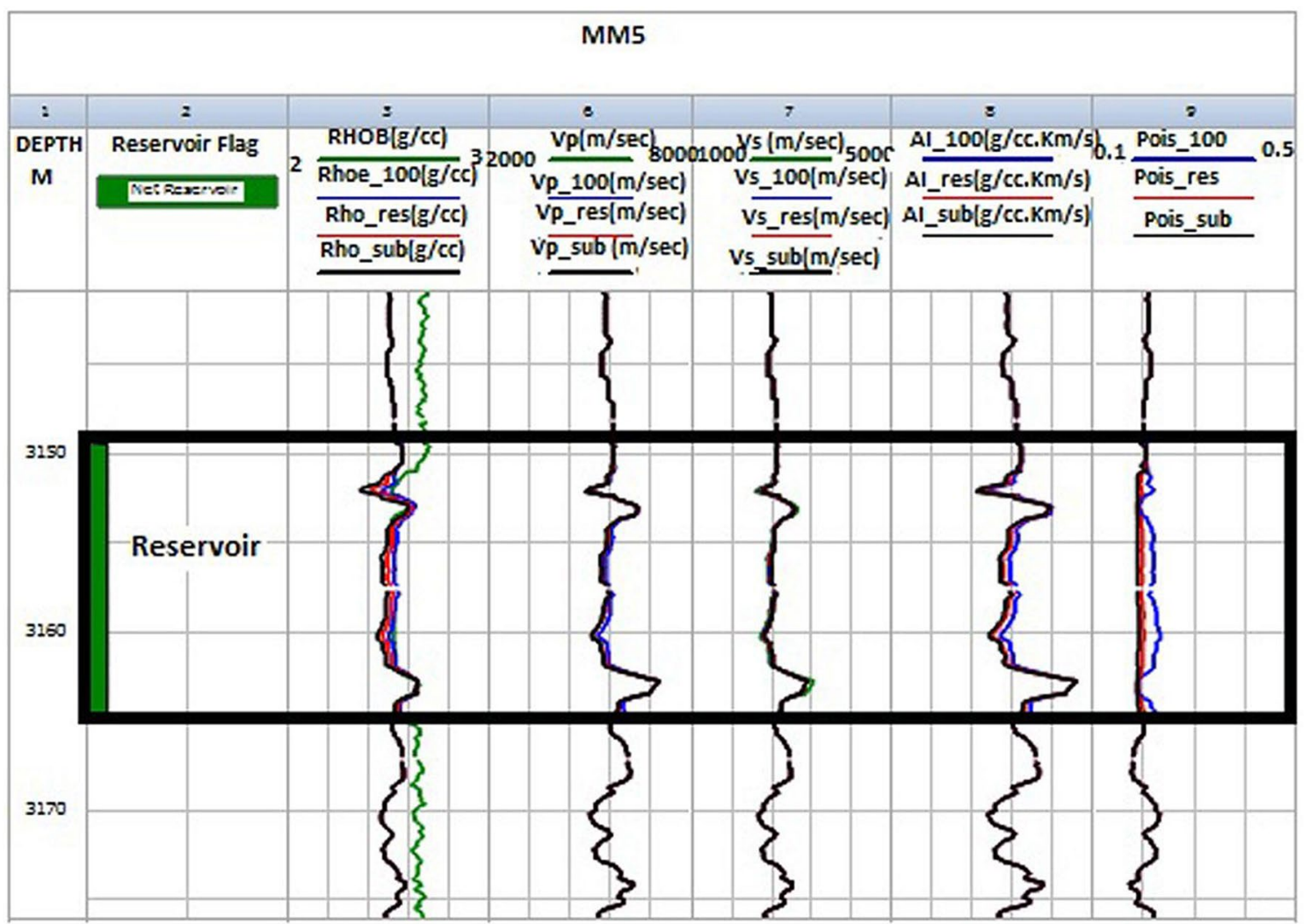

Fig. 13 Elastic impedance logs for MM5 well showing the calculated parameters (Vp, Vs, Al, and poison ratio) at different saturation levels $(100 \%$ water saturation and gas and oil) in the reservoir intervals

This procedure requires that the effect of the initial fluid be removed before modelling the new fluid. The input data (density, water saturation, invaded zone water saturation, and Vclay) were obtained from the reservoirs' petrophysical analyses, whereas Vp and Vs were obtained from the Greenberg and Castagna (1992) method. The shear velocity versus compressional velocity quality control cross-plot is presented in Fig. 10. The Greenberg-Castagna sandstone trendline was used for lithology identification within the reservoir. From Fig. 10, it could be observed that a cluster of points aligned with the sandstone trendline and this indicates that a large portion of the reservoir is a sandstone. Three fluid substitution models (brine, oil, and gas) were determined for pure sandstone and were used to measure the behaviour of the different sandstone saturations. The results of the saturation models are presented in Tables 2 , $3,4,5$, and 6. The fluid substitution cross-plots (Fig. 16a-e) give a clear indication of the relationship between velocities ( $\mathrm{Vp}$ and $\mathrm{Vs}$ ), densities, and water saturation. The $\mathrm{Vp}$ in MM5 (Fig. 16a) showed a drastic increase in velocity, with water saturation displaying a steep slope from $0 \%$ to $100 \%$ water saturation. Well MM3 showed a gradual decrease in $\mathrm{Vp}$ below $70 \%$ water saturation before increasing drastically from $80 \%$ water saturation onwards (Fig. 16e). Well MM1
(Fig. 16b) showed a similar trend to MM3, but with a less gradual decrease in Vp below $70 \%$ water saturation. Well MM4 (Fig. 16d) showed a lower Vp below 70\% water saturation and an increase from $75 \%$ to $100 \%$ water saturation. The Vp in MM2 (Fig. 10c) showed a drastic decrease in Vp below $80 \%$ water saturation, before drastically increasing from $81 \%$ onwards showing a very steep.

A significant decrease was observed in the $\mathrm{Vp}$ when the initial water saturation was substituted with hydrocarbon (oil or gas) in all the wells. The value of density decreased quite visibly in all the wells when the brine $(100 \%$ water saturation) was substituted with gas or oil.

The fluid substitution affected the rock properties significantly. The rock physical properties (Vp, Vs, and density) changed, depending on the level and type of pore fluid saturations. The average Gassmann results are listed in Tables 2, $3,4,5$, and 6 . The poison ratio ranged from 0.167 to 0.226 , as indicated in Figs. 11, 12, 13, 14, 15, and 16 and Tables 2, $3,4,5$, and 6 . The dry rock properties (bulk modulus, shear modulus, poison ratio, and modulus) for the five wells showed different values, indicating the differences in the compaction level of clastic rocks in the study area.

The Vp slightly decreased when brine was substituted with water in wells MM1, MM2, MM3, and MM4. Well MM5 


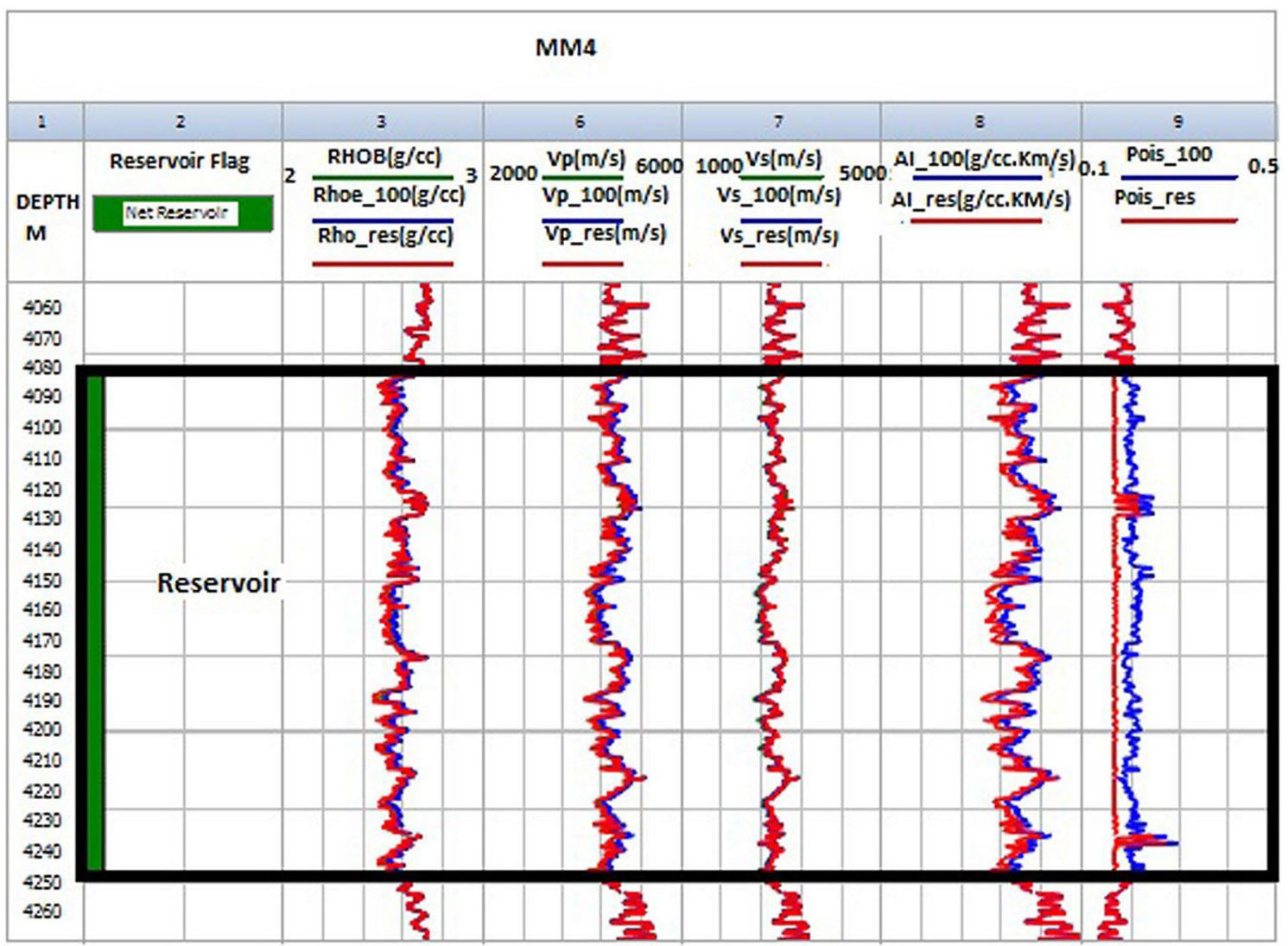

Fig. 14 Elastic impedance logs for MM4 well showing the calculated parameters (Vp, Vs, Al, and poison ratio) at different saturation levels (100\% water saturation and gas) in the reservoir intervals

contained both oil and gas and therefore showed a notable decrease from brine to oil and from oil to gas, respectively. The Vs remained unaffected in all the wells. The acoustic impedance (AI) logs showed a significant decrease from $100 \%$ water saturation to gas saturation in MM3, and slight decrease in MM1, MM2, and MM4. A slight decrease in acoustic impedance was also observed from $100 \%$ water saturation to oil and from oil saturation to gas saturation in well MM5. The change in the acoustic impedance contrast was caused by the change in density and $\mathrm{Vp}(\mathrm{Al}$ being the product of $\mathrm{Vp}$ and density).

\section{Summary and conclusions}

The characterisation of the USM sandstone reservoir units encountered in five wells was made possible by integrating rock physics and petrophysics through a detailed analysis and interpretation of well logs and core data within the quality limits and the amount of available data.
- The gamma-ray log was used to delineate five potential reservoirs-one reservoir per well. The results showed the delineated reservoir intervals having average effective porosity ranging from $8.7 \%$ to $16.6 \%$, indicating a fair to a good quality reservoir. The average $\mathrm{Vcl}$, water saturation, and permeability values ranged from $8.6 \%-22.3 \%$, $18.9 \%-41.6 \%$, and $0.096 \mathrm{mD}-151.8 \mathrm{mD}$, respectively.

- The distribution of the petrophysical properties across the field was clearly defined with MM2 and MM3 showing good porosity, and MM1, MM4, and MM5 showing fair porosity. Well MM4 showed poor permeability, and MM3 showed good permeability.

- The Gassmann equation, using rock frame properties, was used to calculate the effects of fluid substitution on seismic properties.

- Three fluid substitution models (brine, oil, and gas) were determined for pure sandstone and were used to measure the behaviour of the different sandstone saturations. A significant decrease was observed in $\mathrm{Vp}$ when the initial water saturation was substituted with the hydrocarbon 


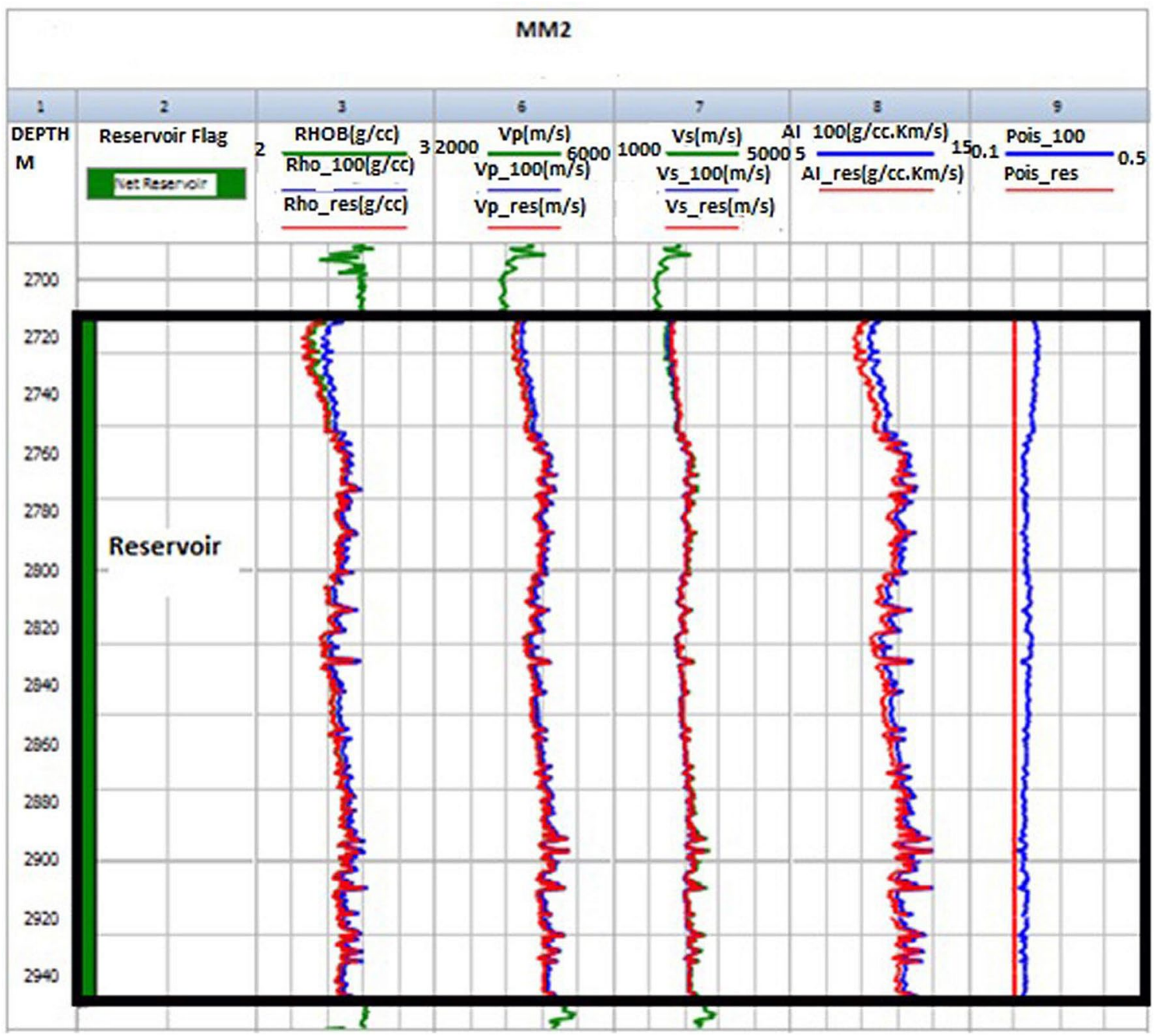

Fig. 15 Elastic impedance logs for MM2 well showing the calculated parameters (Vp, Vs, Al, and poison ratio) at different saturation levels ( $100 \%$ water saturation and gas) in the reservoir intervals

(oil or gas) in all the wells. The density values decreased quite visibly in all the wells when the brine (100\% water saturation) was substituted with gas or oil.

- Fluid substitution significantly affected rock property. The Vp decreased slightly when brine was substituted with gas in wells MM1, MM2, MM3, and MM4. Well MM5 contained both oil and gas and therefore showed a notable decrease from brine to oil and from oil to gas respectively. The Vs remained unaffected in all the wells. The acoustic impedance logs showed a significant decrease from $100 \%$ water saturation to gas saturation in MM3, and a slight decrease in MM1, MM2, and MM4. 
Fuid Substitution - Oil/ Brine MM5

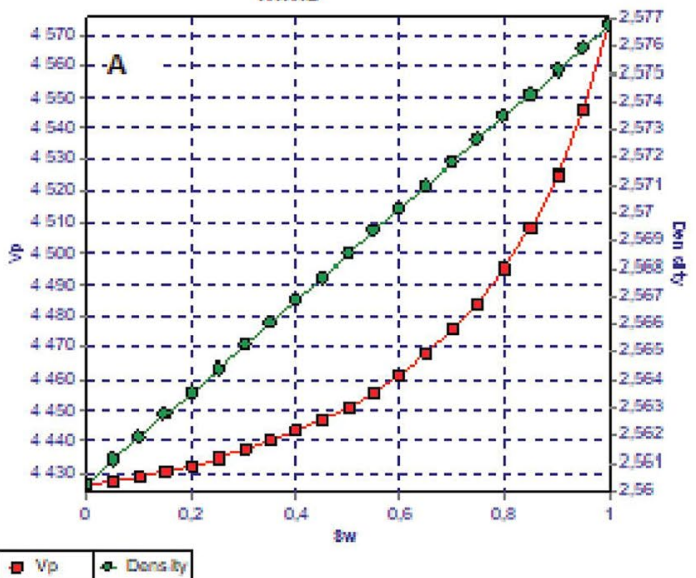

Fluid Substitution - Gas / Brine

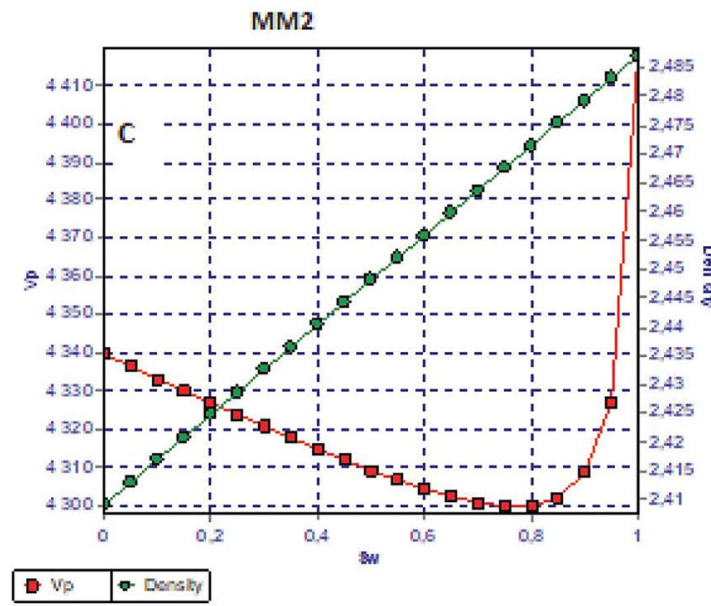

Fluid Substitution - Gas / Brine

MM1

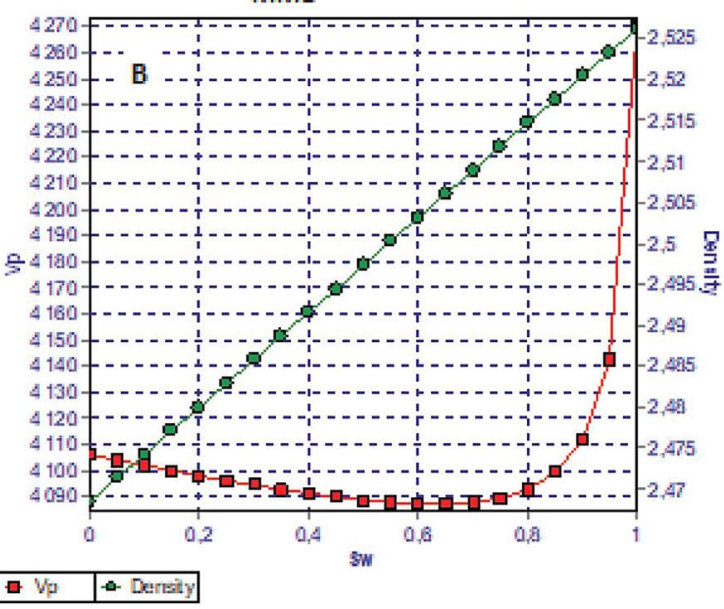

Fluid Substitution - Gas/ Brine MN4

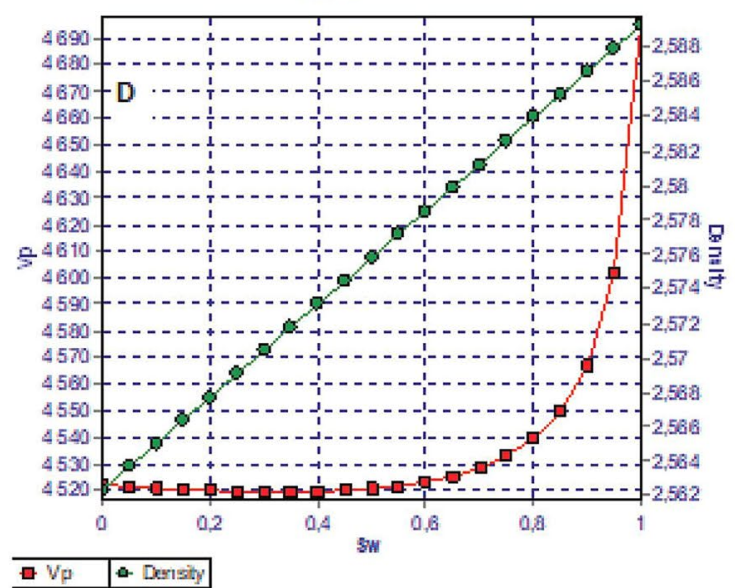

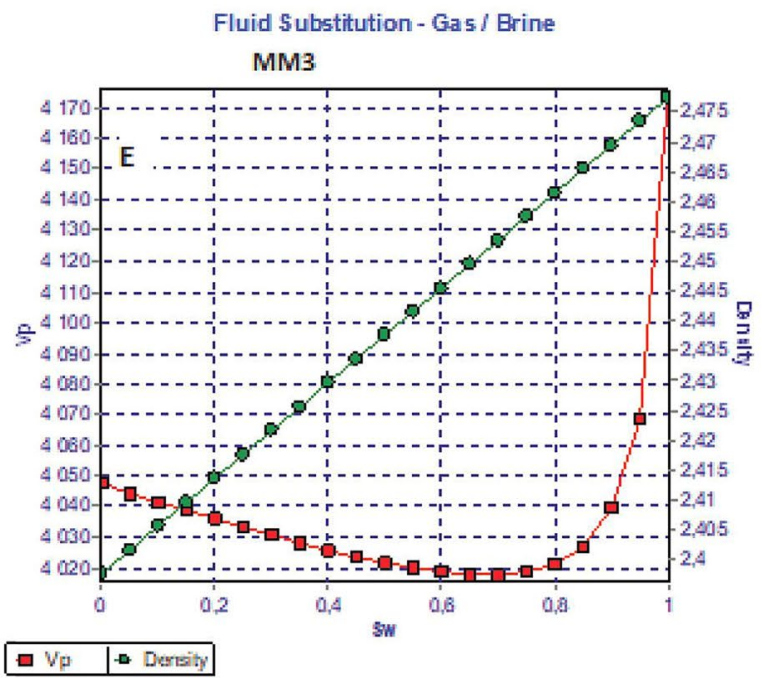

Fig. 16 Fluid substitution cross-plots of a MM5, b MM1, c MM2, d MM4, and e MM3 showing changes in VP for the reservoir intervals in five wells 
Acknowledgements The authors thank the Petroleum Agency of South Africa for providing the data used for this study. They also acknowledge the PETROLAB at the University of Haifa for granting them access to laboratory equipment allowing them to perform their measurements.

Open Access This article is distributed under the terms of the Creative Commons Attribution 4.0 International License (http://creativeco mmons.org/licenses/by/4.0/), which permits unrestricted use, distribution, and reproduction in any medium, provided you give appropriate credit to the original author(s) and the source, provide a link to the Creative Commons license, and indicate if changes were made.

\section{References}

Bisht BS, Sas SK, Chaudhuri PK, Singh RBN, Singh SK (2013) Integration of petrophysics and rock-physics modelling in single workflow reduces uncertainty in seismic reservoir characterization: a case study. Geohorizons 44-47

Bodunde SS, Enikanselu PA (2018) Integration of 3-D seismic and petrophysical analysis with rock physics analysis in the characterization of SOKAB field, Niger delta, Nigeria. J Pet Explor Prod Technol 9:899-909

Clavier C, Hoyle WR, Meunier D (1971) Quantitative interpretation of TDT logs: parts I and II. J Petrol Technol 23:743-763

Crain 2014 www.spec2000.net/14-swbasics.htm

Dakhelpour-Ghoveifel J, Shegeftfard M, Dejam M (2018) Capillarybased method for rock typing in transition zone of carbonate reservoirs. J Pet Explor Prod Technol 9:2009-2018

Dewar J (2001) Rock physics for the rest of us: an informal discussion. Recorder 26(5):42-49

El-Bahiry M, El-Amir A, Abdelhay M (2017) Reservoir characterization using fluid substitution and inversion methods, offshore West Nile Delta, Egypt. Egypt J Pet 26(2):351-361

Gassmann F (1951) Elastic waves through a packing of spheres. Geophysics 16:673-685

Gommesen L, Mavko G, Mukerji T, Fabricius IL (2002) Fluid substitution studies for North Sea chalk logging data. In: Proceedings of the SEG annual meeting, October 6-11, 2002, Salt Lake City, Utah

Greenberg ML, Castagna JP (1992) Shear-wave velocity estimation in porous rocks: theoretical formulation, preliminary verification and applications. Geophys Prospect 40(2):195-209

Hilchie DW (1978) Applied open hole log interpretation. D.W. Hilchie Inc, Colorado
Jensen JL, Ayers WB, Blasingane TA (2013) Introduction to shaley sand analysis. Department of Petroleum Engineering. Texas A and M University, Texas

Jensen EH, Johansen TA, Avseth P, Bredesen K (2016) Quantitative interpretation using inverse rock-physics modelling on AVO data. Lead Edge 35(8):677-683

Khan N, Rehman K (2018) Petrophysical evaluation and fluid substitution modeling for reservoir depiction of Jurassic Datta Formation in the Chanda oil field, Khyber Pakhtunkhwa, northwest Pakistan. J Pet Explor Prod Technol 9:1-18

Larionov V (1969) Radioactivity by well log. Nedra, Moscow (in Russian)

McMilian IK, Brink GJ, Broad DS, Maier JJ (1997) Late Mesozoic sedimentary basins off the south coast of South Africa. Sediment Basins World 3:319-376

Mudaly K, Turner J, Escorcia F, Higgs R (2009) F-O gas field, Offshore South Africa-From Integrated approach to field development. American Association of Petroleum Geologist (AAPG) Search and Discovery Article \#20070

Poupon A, Leveaux J (1971) Evaluation of water saturation in shaly formations. Trans SPWLA 12th annual logging symposium, vol 2

Purnamasari IA, Khairy H, Abdeldayem AL, Ismail W (2014) Rock physics modeling and fluid substitution studies in sandstone reservoir. J Appl Sci 14:1180-1185

Rider M (2002) The geological interpretation of well logs: Sutherland. Rider-French Consulting Ltd, Scotland

Simandoux P (1963) Dielectric measurements on porous media, application to the measurements of water saturation: study of behavior of argillaceous formations. Revue de l'Institut Francais du Petrol 18(suppl):93-215

Smith TM, Sondergeld CH, Rai CS (2003) Gassmann fluid substitutions: a tutorial. Geophysics 68(2):430-440

Stieber SJ (1970) Pulsed neutron capture log evaluation-Louisiana gulf coast. In Fall meeting of the society of petroleum engineers of AIME. Society of Petroleum Engineers

Turner JR, Grobbler N, Sontundu S (2000) Geological modelling of the Aptian and Albian sequences within Block 9, the Bredasdorp Basin, offshore South Africa. J Afr Sci 31(1):80

Publisher's Note Publisher's Note Springer Nature remains neutral with regard to jurisdictional claims in published maps and institutional affiliations 